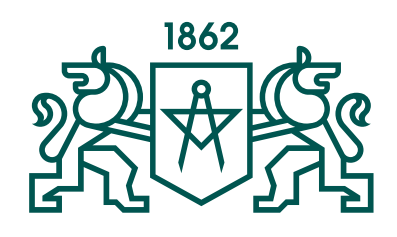

RIGA TECHNICAL UNIVERSITY

Inna Kurbatska

\title{
EVALUATION OF MODULATION FORMATS FOR THE NEXT GENERATION FIBER OPTICAL ACCESS TELECOMMUNICATION SYSTEMS
}

Summary of the Doctoral Thesis

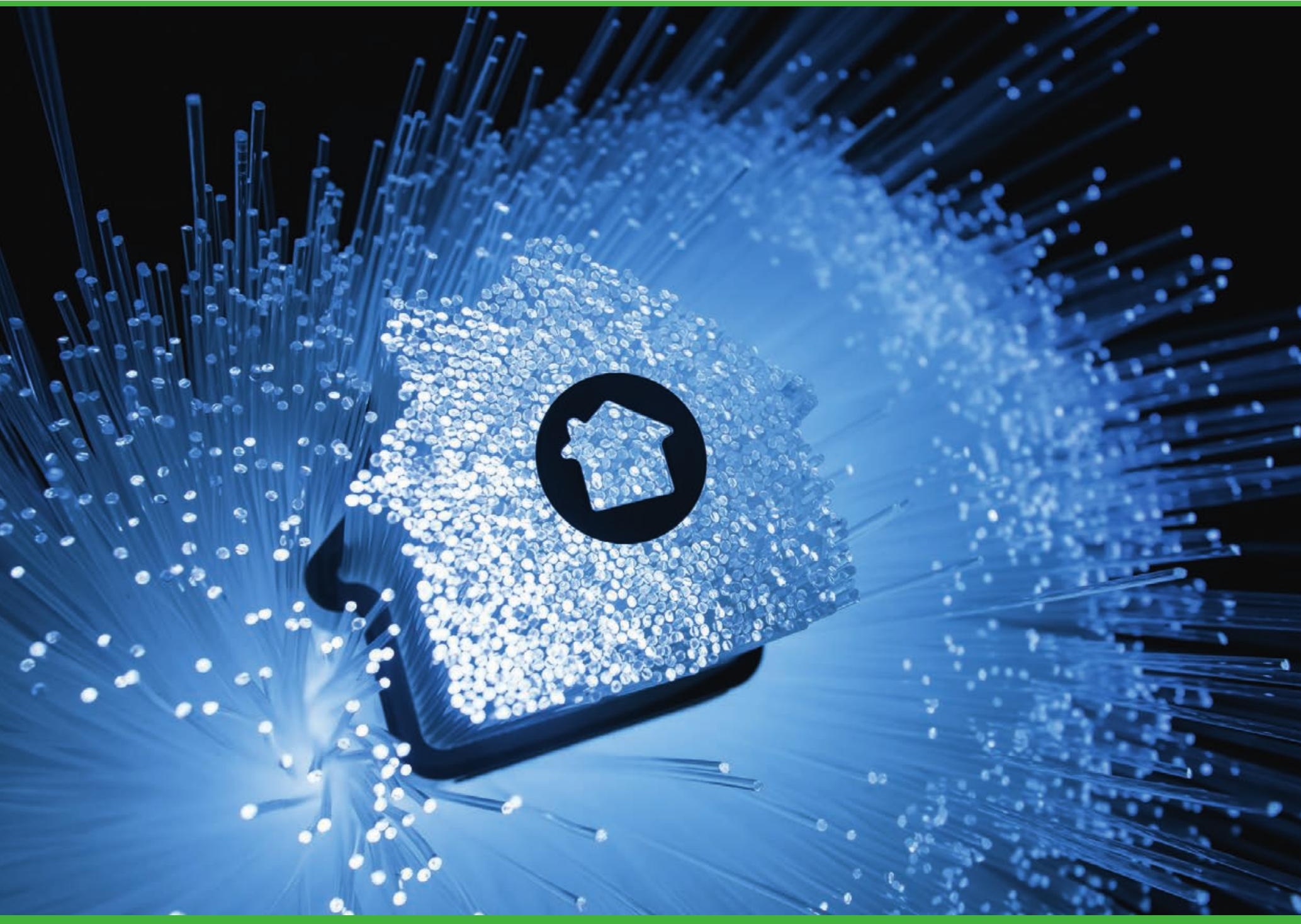

RTU Press

Riga 2019 


\title{
RIGA TECHNICAL UNIVERSITY
}

Faculty of Electronics and Telecommunications

Institute of Telecommunications

\author{
Inna Kurbatska
}

Doctoral Student of the Study Programme "Telecommunications"

\section{EVALUATION OF MODULATION FORMATS FOR THE NEXT GENERATION FIBER OPTICAL ACCESS TELECOMMUNICATION SYSTEMS}

Summary of the Doctoral Thesis

Scientific supervisors

Professor Dr. sc. ing. VJAČESLAVS BOBROVS Associate Professor Dr. sc. ing.

SANDIS SPOLĪTIS

RTU Press

Riga 2019 
Kurbatska, I. Evaluation of Modulation Formats for the Next Generation Fiber Optical Access Telecommunication Systems. Summary of the Doctoral Thesis. Riga: RTU Press, 2019. 36 pp.

Published in accordance with the decision of Promotion Council "RTU P-08" of 4 April 2019, Minutes No. 44. 


\section{DOCTORAL THESIS PROPOSED TO RIGA TECHNICAL UNIVERSITY FOR THE PROMOTION TO THE SCIENTIFIC DEGREE OF DOCTOR OF ENGINEERING SCIENCES}

To be granted the scientific degree of Doctor of Engineering Sciences, the present Doctoral Thesis has been submitted for the defence at the open meeting of RTU Promotion Council on June 27, 2019 at the Faculty of Electronics and Telecommunications of Riga Technical University, 12 Āzenes Street, Room 201.

\section{OFFICIAL REVIEWERS}

Professor, Dr. habil. sc. ing. Ernests Pētersons

Riga Technical University

Researcher, Dr. phys. Irēna Mihailova

Daugavpils University, Latvia

Researcher, Dr. phys. Edgars Elsts

University of Latvia, Latvia

\section{DECLARATION OF ACADEMIC INTEGRITY}

I hereby declare that the Doctoral Thesis submitted for the review to Riga Technical University for the promotion to the scientific degree of Doctor of Engineering Sciences is my own. I confirm that this Doctoral Thesis had not been submitted to any other university for the promotion to a scientific degree.

Inna Kurbatska (signature)

Date:

The Doctoral Thesis has been written in Latvian. It consists of Introduction; 4 chapters; Conclusions; 76 figures; 27 tables; 8 appendices; the total number of pages is 133, not including appendices. The Bibliography contains 154 titles. 


\begin{abstract}
ANNOTATION
Exponential growth of the data traffic, high requirements of business users to the security and symmetrical transmission data rate, as well as utilization of access networks for backhaul and fronthaul applications are driving demands on next-generation access networks - fiberoptical access networks with improved parameters (bitrate and transmission distance) in comparison to the solution based on copper cables. However, there is a number of technological issues that have to be solved ensuring high data rate transmission - the choice of the suitable modulation format, the cost and availability of the wideband elements of transmission system, as well as compatibility of the different transmission data rates.

In the Thesis, the most suitable data modulation formats for utilization in wavelength division multiplexed passive optical networks (WDM-PONs) are chosen as well as the main performance-affecting factors are investigated. As a result, the model of mixed (with $12.5 \mathrm{Gbit} / \mathrm{s}$ and $25 \mathrm{Gbit} / \mathrm{s}$ data transmission rates) WDM-PON access telecommunication system is developed (including the approach of modelling of Mach-Zehnder modulator frequency response). The solution of mixed WDM-PON access network with values and limits of the main performance-affecting factors is proposed.
\end{abstract}




\section{CONTENTS}

ABBREVIATIONS




\section{ABBREVIATIONS}

\section{A}

AFR - Amplitude Frequency Response

AON - Active Optical Network

\section{B}

BER - Bit Error Ratio

BF - Bessel Filter

BW - Bandwidth

C

CL - Confidence Level

CRZ - Chirped Return to Zero

CSRZ - Carrier-Suppressed-Return-to-Zero

\section{D}

DB - Duobinary

DPSK - Differential Phase Shift Keying

DQPSK - Differential Quadrature Phase Shift Keying

E

EDFA - Erbium Doped Fiber Amplifier

F

FEC - Forward Error Correction

FOAS - Future Optical Access System

FSAN -Full Service Access Network

FTTB - Fiber to the Building

FTTH - Fiber to the Home

FTTx - Fiber to the $\mathrm{x}$

G

GF - Gaussian filter

GPON - Gigabit Passive Optical Network

I

ITU - International Telecommunications Union

M

MLR - Mixed Line Rate

MMF - Multiple Modulation Formats 
MZM - Mach-Zehnder Modulator

$\mathbf{N}$

NGA - Next Generation access

NG-PON - Next Generation Passive Optical Network

NRZ - Non-Return-to-Zero

\section{$\mathbf{O}$}

ODN - Optical Distribution Network

OOK - On-Off Keying

\section{$\mathbf{P}$}

PAM-4 - 4-level Pulse Amplitude Modulation

PON - Passive Optical Network

PSK - Phase Shift Keying

$\mathbf{R}$

REH - Relative Eye Height

RZ - Return-to-Zero

RIN - Relative Intensity Noise

W

WDM - Wavelength Division Multiplexing

WDM-PON - Wavelength Division Multiplexed Passive Optical Network

WS-WDM-PON - wavelength-selected WDM-PON

WR-WDM-PON - wavelength-routed WDM-PON 


\section{GENERAL DESCRIPTION OF THE RESEARCH}

\section{Topicality of the Research}

Nowadays, different broadband applications (3D-HD video, e-health, e-learning, multiplayer games, etc.) are widely used, as a result the data traffic of the internet users is growing exponentially [26]. Moreover, additional requirements such as high security and symmetrical transmission data rate became spatially critical for business clients. It is also important that nowadays access networks are widely utilized for backhaul and fronthaul applications, for example, connections between wireless network antennas, base stations of the mobile network or security and surveillance systems [4], [9], [24], [26], [28], [32], [33], [37]. It results in the demand on the next-generation access (NGA) systems. NGA systems are wire access systems that in full extend or partly consist from optical fiber elements and are capable to ensure access services with the improved parameters (e.g. higher network capacity, longer transmission distance) in comparison with the parameters ensured by existing access networks where copper cables are utilized [6].

It is worth noting, that it is only possible to ensure the mentioned advantages of fiber optics in full extend only if the fully optical solution, i.e. fiber to the home/building (FTTH/B) is utilized [9], [10]. While analyzing the possibilities of realization of passive and active FTTH/B solution, it was concluded that passive optical network (PON) is more widely used in already implemented FTTH/B solutions (also in Latvia), and consequently is more demanding [8], [11], [43].

Actual tendencies of the development of PON technologies are shown in the PON roadmap offered by full-service access network (FSAN) organization (Fig. 1).

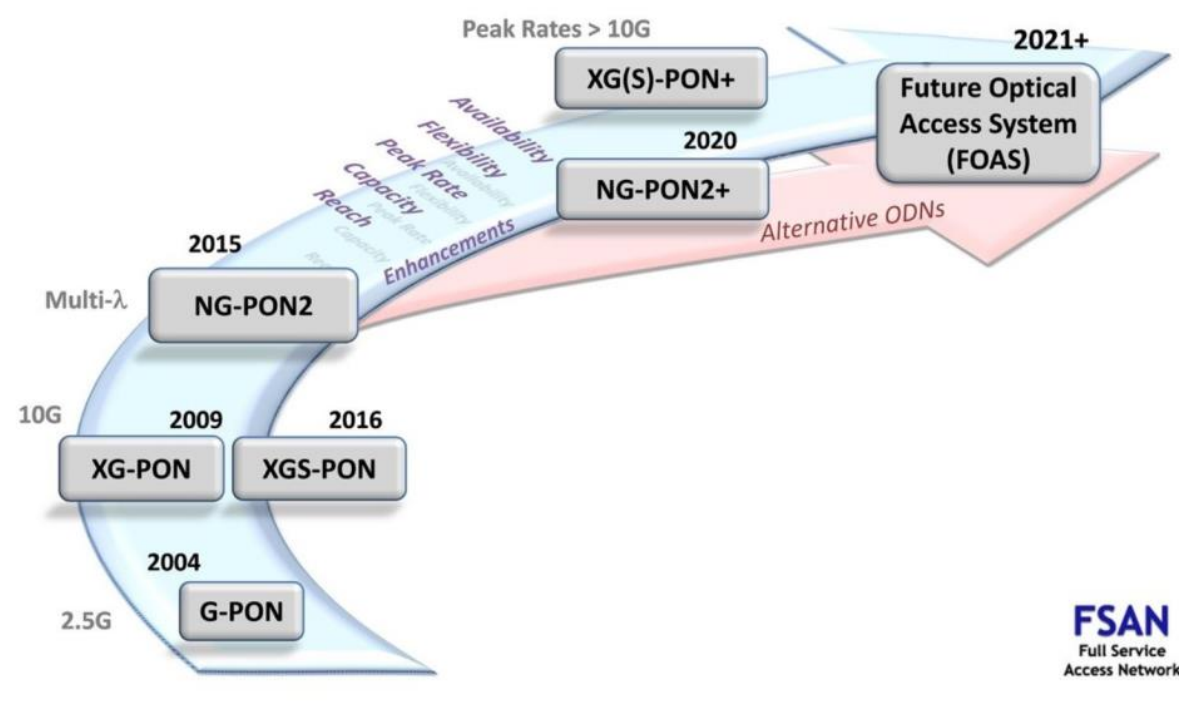

Fig. 1. PON roadmap proposed by FSAN [40].

Up to this moment, PON solutions are mainly implemented according to the ITU-T G.984 recommendation (gigabit PON, (G-PON)) utilizing time division multiplexing (TDM) and non-return-to-zero on-off keying (NRZ-OOK) [15], [39]. Whereas future development of PON 
is defined using the term next-generation PON (NG-PON). Moreover, if the aim of 10G-PON (XG-PON) (ITU-T G.987) and XGS-PON (symmetric XG-PON) is only the increase of data transmission rate (from $2.5 \mathrm{Gbit} / \mathrm{s}$ to $10 \mathrm{Gbit} / \mathrm{s}$ downstream, from $1.24 \mathrm{Gbit} / \mathrm{s}$ to $2.5 \mathrm{Gbit} / \mathrm{s}$ and $10 \mathrm{Gbit} / \mathrm{s}$ upstream), then the latest ITU-T recommendation (ITU-T G.989, NG-PON2) assumes the utilization of wavelength division multiplexing.

It should be emphasized that beginning with 2015 the new direction of PON development, i.e. future optical access systems (FOAS), has been established. It assumes the utilization of alternative optical distribution network (ODN) (Fig. 1), and, consequently, ensures the possibility to implement wavelength routed WDM-PON (WR-WDM-PON). WR-WDM-PON (that is utilized in the Thesis) is a new, advanced solution with several advantages (security, power budget, non-tuneable receivers). It is worth mentioning, that, considering that WRWDM-PON is a future solution, the emphasis in the Thesis was put on the development of the reliable model of the solution, as it is possible to utilize the model not only for the choice of the elements of the transmission system and the definition of the limits of the main parameters, but also for the enhancement of the elements of the transmission systems as well as for the evaluation of the enhanced elements. Based on the analysis of the topicality of data transmission rates [16], [24], [40], the possibilities of implementation of WR-WDM-PON with 10 Gbit/s, $25 \mathrm{Gbit} / \mathrm{s}$ and $40 \mathrm{Gbit} / \mathrm{s}$ per-wavelength data rates are evaluated in the Thesis. In turn, the emphasis was on the choice of the appropriate data modulation format as well as on the coexistence of the different data transmission rates. It is worth mentioning that data modulation formats were evaluated considering their performance, the complexity of the implementation as well as demands on the bandwidth of the elements of the transmission system. In the Thesis, the traditionally used NRZ-OOK data modulation format is compared to the following data modulation formats: Duobinary (DB), 4-level pulse amplitude modulation (PAM-4), on-off keying (OOK) with return-to-zero (RZ) and carrier-suppressed-return-to-zero (CSRZ) coding as well as differential phase shift keying (DPSK) with NRZ, RZ and CSRZ coding.

\section{The Aims and Tasks of the Thesis}

Upon summing up the aforementioned facts, the following aim of the Doctoral Thesis was proposed - to choose the most appropriate data modulation formats for the utilization in WDMPON transmission systems and to develop the model of the combined access communication system in VPI Design Suite software.

To achieve the aim, it was necessary to perform the following key tasks.

1. To evaluate the performance (ensured BER, transmission distance) of NRZ-OOK, RZOOK, CSRZ-OOK, NRZ-DPSK, RZ-DPSK, CSRZ-DPSK, DB and PAM-4 modulation formats in WDM-PON transmission systems.

2. To evaluate the impact of the parameters of the continuous wave laser, Mach-Zehnder modulator, arrayed waveguide grating multiplexer and demultiplexer, optical fiber as well as PIN photoreceiver on BER and minimum received optical signal power in WDM-PON transmission system with DB, PAM-4 and NRZ data modulation formats with up to $40 \mathrm{Gbit} / \mathrm{s}$ per-wavelength data transmission rates. 
3. Considering the requirements of ITU-T G.989.2 recommendation, to define the parameters of the mixed access communication system (data transmission rate, modulation formats, transmitter and receiver bandwidth) and to develop the model of the mixed WDM-PON solution, that assumes the utilization of the chosen data rates and modulation formats in one passive optical network.

4. To evaluate the impact of the Mach-Zehnder modulator amplitude-frequency response on the BER of PAM-4 modulated channels with $25 \mathrm{Gbit} / \mathrm{s}$ data transmission rate, and as a result to define the approach for the modelling of amplitude-frequency response of the modulator.

5. To experimentally evaluate the feasibility of implementation of PAM-4 modulation format with $25 \mathrm{Gbit} / \mathrm{s}$ data rate and to improve the developed model of the mixed WDMPON solution.

6. To evaluate the reciprocal impact of the main limiting factors (dispersion, minimal received optical signal power, thermal noise of the receiver as well as amplitudefrequency response of the transmitter) of the mixed $25 \mathrm{Gbit} / \mathrm{s}$ (PAM-4) and $12.5 \mathrm{Gbit} / \mathrm{s}$ (NRZ) WDM-PON transmission system and, as a result, to define the limits for ensuring BER below FEC thresholds for PAM-4 modulated channels.

\section{The Research Methods}

For the realization of the tasks proposed in Thesis, mathematical calculations, numerical simulations as well as experimental measurements were performed.

The numerical simulations were performed utilizing two different softwares for simulation of fiber optic transmission systems (Rsoft OptSim and VPI Design Suite) with block-oriented simulation methodology. The initial investigation of the utilization of modulation formats in WDM-PON access transmission systems (utilizing OptSim software) were performed in the variable bandwidth sample mode. Whereas the main results of the Thesis were obtained in single frequency band and block mode (utilizing VPI Design Suite software). In both cases, optical fiber was simulated by split-step method. The experimental part of the research was performed in the laboratory of fiber optical transmission systems of the Institute of Telecommunications of Riga Technical University.

The values of the signal power as well as signal spectrums were used for the assessment of the optical signal quality. While the assessment of the quality of the received electrical signals was performed using bit-error-ratio (BER), it was mainly calculated by analytical method. In some cases, the quality factor ( $Q$-factor) was used. The eye diagrams were used for the additional evaluation of the electrical signal quality.

\section{Research Results and Scientific Novelty}

\section{Novel achievements of the Doctoral Thesis are as follows}

1. The use of several modulation formats (NRZ-OOK, RZ-OOK, CSRZ-OOK, NRZDPSK, RZ-DPSK, CSRZ-DPSK, DB and PAM-4) was evaluated in WR-WDM-PON transmission system, as a result, the most suitable modulation formats for the 
corresponding transmission system were selected as well as the advantages of their utilization were determined.

2. The BER affecting factors were evaluated for DB and PAM-4 modulated high data rate (above $25 \mathrm{Gbit} / \mathrm{s}$ ) WR-WDM-PON transmission system, as a result the transmission system parameters, limits of which it is crucial to evaluate when choosing the elements of the transmission system or when performing the reliable mathematical simulation of the corresponding transmission system, were detected.

3. Based on the analysis of the impact of the amplitude-frequency response (AFR) of the Mach-Zehnder modulator, the approach for the modelling of the transmitter AFR for PAM-4 modulated WR-WDM-PON transmission system with $25 \mathrm{Gbit} / \mathrm{s}$ perwavelength data transmission rate was defined, as a result the Matlab program for the calculation of AFR model was developed.

4. Considering the parameters of the commercially available elements, the model of mixed WR-WDM-PON transmission system was developed in VPI Design Suite software (applicable also to WS-WDM-PON and TWDM-PON transmission systems), that ensures the determination of the limits of the main performance-affecting factors, that can be used as guidelines for the choice of the elements that are necessary for implementation of the corresponding transmission systems and the enhancement of the elements, as well as the assessments of the enhanced elements.

5. The mixed $12.5 \mathrm{Gbit} / \mathrm{s}$ (NRZ) and $25 \mathrm{Gbit} / \mathrm{s}$ (PAM-4) WR-WDM-PON solution is proposed as well as values or limits of the main performance affecting factors (chromatic dispersion, minimum received power, transmitter amplitude-frequency response) for ensuring the transmission with BER below $1 \times 10^{-3}$ threshold were determined.

\section{The following main conclusions have been drawn during the development of the Doctoral Thesis}

1. By evaluating the performance (BER, transmission distance) of the different modulation formats (NRZ-OOK, RZ-OOK, CSRZ-OOK, NRZ-DPSK, RZ-DPSK, CSRZ-DPSK, DB, PAM-4) in WR-WDM-PON transmission systems, it was concluded that for the transmission up to $20 \mathrm{~km}$ with $10 \mathrm{Gbit} / \mathrm{s}$ data transmission rate it is necessary to utilize the NRZ-OOK modulation format that is technically simpler to implement, while for longer transmission distances ( $40 \mathrm{~km}$ to $60 \mathrm{~km}$ ) the DB modulation format should be utilized (ensuring the BER reserve of at least 6 BER powers).

2. To perform the increase of the data transmission rate above $25 \mathrm{Gbit} / \mathrm{s}$ per-channel, it is necessary to substitute NRZ-OOK with another data modulation format (PAM-4 or DB) to ensure the transmission distances longer than $5 \mathrm{~km}$ with $40 \mathrm{Gbit} / \mathrm{s}$ or longer than 15 $\mathrm{km}$ with $25 \mathrm{Gbit} / \mathrm{s}$ data transmission rate.

3. It is possible to utilize the transmitters and receivers intended for the transmission with $10 \mathrm{Gbit} / \mathrm{s}$ data rate in WDM-PON transmission system with $25 \mathrm{Gbit} / \mathrm{s}$ per-channel data transmission rate, as well as to ensure channel spacing of $50 \mathrm{GHz}$ if the PAM-4 modulation format is utilized, whereas utilizing DB modulation format with transmitters 
and receivers intended for $20 \mathrm{Gbit} / \mathrm{s}$ data transmission rate and $100 \mathrm{GHz}$ channel spacing, it is possible to ensure BER below $1 \times 10^{-3}$ with $3 \mathrm{~dB}$ smaller received optical signal power (in comparison to PAM-4).

4. In the PAM-4 modulated WR-WDM-PON transmission system with the per-channel data rate of $25 \mathrm{Gbit} / \mathrm{s}$ the smallest BER is ensured if the spectrum of the signal in the transmitter is kept in frequency band before $10 \mathrm{GHz}$, whereas from 10 to $15 \mathrm{GHz}$ it is filtered, moreover the amplitude-frequency response around $0 \mathrm{~Hz}$ has significant impact on BER (about five BER powers).

5. In the mixed $12.5 \mathrm{Gbit} / \mathrm{s}$ (NRZ) and $25 \mathrm{Gbit} / \mathrm{s}$ (PAM-4) WDM-PON transmission system, the utilization of MLR mixed solution, as well as decrease of the channel spacing to $50 \mathrm{GHz}$ does not affect the performance (BER, minimal received optical signal power) of transmission system significantly (not more than one BER power or 1 $\mathrm{dB}$ ), while the main factors that affect the transmission of PAM-4 channels, similarly to 25 Gbit/s (PAM-4) WDM-PON, are the following: chromatic dispersion, amplitudefrequency response of the transmission system, the thermal noise of the receiver and pulse rise time.

\section{The Practical Value of the Research}

- The new setup of the PAM-4 modulated transmission system with 25 Gbit/s data rate and transmission distance up to $25 \mathrm{Gbit} / \mathrm{s}$ per-channel was developed in the Laboratory of Fiber Optical Transmission Systems.

The results of the scientific research of the Doctoral Thesis have been applied in the implementation of the following projects

- ESF project: "Establishment of ICT Group for Transmission, Processing and Management of Large Data Amounts”. Project No. 2013/0012/1DP/1.1.1.2.0/13/ APIA/VIAA/051.

- ERDF project "Improvement of accessibility of electronic communications infrastructure in rural areas." Nr. 2.1.1.0/16/I/001.

- ERDF project "Passive fiber optical sensors for energy efficient health monitoring of transport infrastructure." Nr. 1.1.1.1/16/A/072.

- ERDF project "Next-Generation High-Speed Fiber Optical Access Systems (NGFAST).” Nr. 1.1.1.2/VIAA/1/16/044.

\section{Thesis Statements to Be Defended}

1. Implementing mixed WR-WDM-PON transmission system with $10 \mathrm{Gbit} / \mathrm{s}$ and $25 \mathrm{Gbit} / \mathrm{s}$ per-wavelength data transmission rates and $20 \mathrm{~km}$ transmission distance it is necessary to utilize the following structure of the channels: NRZ-OOK data modulation format for $10 \mathrm{Gbit} / \mathrm{s}$ channels; PAM-4 data modulation format - for $25 \mathrm{Gbit} / \mathrm{s}$ channels.

2. In the WR-WDM-PON transmission systems with $25 \mathrm{Gbit} / \mathrm{s}$ data rate and PAM-4 data modulation formats the amplitude-frequency response of Mach-Zehnder modulator can 
be modelled with the difference in the obtained BER, that does not exceed one power, based on the values of AFR in $0 \mathrm{~Hz},-1 \mathrm{~dB}$ and $-3 \mathrm{~dB}$ points.

3. In the mixed up to $12.5 \mathrm{Gbit} / \mathrm{s}$ (NRZ) and $25 \mathrm{Gbit} / \mathrm{s}$ (PAM-4) WDM-PON transmission system, it is possible to ensure the transmission at $20 \mathrm{~km}$ in optical C-band with BER that does not exceed $1 \times 10^{-3}$ utilizing the transmitter and receiver with $-3 \mathrm{~dB}$ bandwidth that does not exceed $10 \mathrm{GHz}$, if the -1 bandwidth of PAM-4 transmitter is not smaller than $5 \mathrm{GHz}$, while in optical L-band - utilizing transmitter with $-3 \mathrm{~dB}$ and $-1 \mathrm{~dB}$ bandwidths not smaller than $14 \mathrm{GHz}$ and $8 \mathrm{GHz}$, respectively.

\section{Approbation of Research Results}

The main results of the Doctoral Thesis have been presented in 9 international scientific conferences, reported in $\mathbf{2}$ publications in scientific journals, and in $\mathbf{8}$ publications in full-text conference proceedings.

\section{Reports at international scientific conferences}

1. Kurbatska I., Spolitis S., Bobrovs V., Alsevska A., Ivanovs G. Performance comparison of modulation formats for $10 \mathrm{Gbit} / \mathrm{s}$ WDM-PON systems// Advances in Wireless and Optical Communications (RTUWO). Latvia, Riga, November 3-4, 2016.

2. Kurbatska I., Alsevska A., Gegere L., Bobrovs V. Comparison of modulation formats for use in the next generation passive optical networks// Progress in Electromagnetic Research Symposium (PIERS). China, Shaanxi, August 8- 11, 2016.

3. Kurbatska I., Spolitis S., Ivanovs G., Bobrovs V. Investigation on optimal transmission parameters for different modulation formats in $10 \mathrm{Gbit} / \mathrm{s}$ WDM-PON systems// International Workshop on Fiber Optics in Access Network (FOAN). Portugal, Lisbon, October 18-20, 2016.

4. Kurbatska I., Alsevska A., Gegere L., Bobrovs V. Investigation of influence of mixed Configurations on performance of WDM-PON// Electronics 2017. Lithuania, Palanga, June 19-21, 2017.

5. Kurbatska I., Bobrovs V., Alsevska A., Lyashuk I., Gegere L. Spectral effective solutions for mixed line rate WDM-PON systems// Progress In Electromagnetics Research Symposium - Spring (PIERS). Russia, St. Petersburg, May 22-25, 2017.

6. Spolitis S., Kurbatska I., Bobrovs V. Comparison of C-band and L-band WDM-PON systems performance with PAM-4 modulation format// International Workshop on Fiber Optics in Access Network (FOAN). Germany, Munich, November 6-8, 2017.

7. Kurbatska I., Bobrovs V., Gavars P., Gegere L. Evaluation of the impact of parameters of transmission system on the performance of WDM-PON// Progress in Electromagnetics Research Symposium - Fall (PIERS - FALL). Singapore, Singapore, November 19-22, 2017.

8. Spolitis S., Kurbatska I., Bobrovs V. Considering of PAM-4, DB, NRZ and RZ for Implementation in Next-Generation PONs // 26th International Conference on Software, Telecommunications and Computer Networks (SoftCOM). Croatia, Split, September 13-15, 2018.

9. Spolitis S., Kurbatska I., Bobrovs V. Evaluation of the Channel Spacing and Transceiver Bandwidth for PAM-4 Modulated WDM-PON// Advances in Wireless and Optical Communications (RTUWO). Latvia, Riga, November 15-16, 2018. 


\section{Publications in scientific journals}

1. Kurbatska I., Bobrovs V., Spolitis S., Gavars P., Ivanovs G., Parts, R. Investigation on Maximum Available Reach for Different Modulation Formats in WDM-PON Systems// Latvian Journal of Physics and Technical Sciences. 2016. Vol. 53 (4), pp. 66-75.

2. Kurbatska I., Alsevska A., Gegere L., Bobrovs V. Investigation of influence of mixed Configurations on performance of WDM-PON// Elektronika ir Elektrotechnika. 2017. Vol. 23 (2), pp. 74-78.

\section{Publications in full-text conference proceedings}

1. Kurbatska I., Spolitis S., Bobrovs V., Alsevska A., Ivanovs G. Performance comparison of modulation formats for $10 \mathrm{Gbit} / \mathrm{s}$ WDM-PON systems// Proceedings of Advances in Wireless and Optical Communications (RTUWO). Riga, Latvia, 2016. pp. $51-54$.

2. Kurbatska I., Alsevska A., Gegere L., Bobrovs V. Comparison of modulation formats for use in the next generation passive optical networks// Progress in Electromagnetic Research Symposium (PIERS). Shanghai, China, 2016. pp. 3783-3787.

3. Kurbatska I., Spolitis S., Ivanovs G., Bobrovs V. Investigation on optimal transmission parameters for different modulation formats in $10 \mathrm{Gbit} / \mathrm{s}$ WDM-PON systems// International Workshop on Fiber Optics in Access Network (FOAN). Lisbon, Portugal, 2016. pp. 1-5.

4. Kurbatska I., Bobrovs V., Alsevska A., Lyashuk I., Gegere L. Spectral effective solutions for mixed line rate WDM-PON systems// Progress In Electromagnetics Research Symposium - Spring (PIERS). St. Petersburg, Russia, 2017. pp. 1771-1777.

5. Spolitis S., Kurbatska I., Bobrovs V. Comparison of C-band and L-band WDM-PON systems performance with PAM-4 modulation format// International Workshop on Fiber Optics in Access Network (FOAN). Munich, Germany, 2017. pp. 1-6.

6. Kurbatska I., Bobrovs V., Gavars P., Gegere L. Evaluation of the impact of parameters of transmission system on the performance of WDM-PON// Progress in Electromagnetics Research Symposium - Fall (PIERS - FALL). Singapore, Singapore, 2017. pp. 1370-1376.

7. Spolitis S., Kurbatska I., Bobrovs V. Considering of PAM-4, DB, NRZ and RZ for Implementation in Next-Generation PONs // 26th International Conference on Software, Telecommunications and Computer Networks (SoftCOM). Split, Croatia, 2018. pp. 1-6.

8. Spolitis S., Kurbatska I., Bobrovs V. Evaluation of the Channel Spacing and Transceiver Bandwidth for PAM-4 Modulated WDM-PON// Advances in Wireless and Optical Communications (RTUWO). Riga, Latvia, 2018. pp. 148-153.

\section{The Volume and Structure of the Doctoral Thesis}

The volume of the Doctoral Thesis is 133 pages. It consists of Introduction, four chapters, bibliography and eight appendices.

In Chapter 1 of the Thesis, the suitable FTTH architecture (PON) for the utilization in the Thesis is chosen based on the comparative analysis of the architectures that are used in NGA transmission systems. The development of different PON technologies is also evaluated, as a result the technology (WR-WDM-PON) that will be mainly investigated in the Thesis is chosen. 
Moreover, several data modulation formats that are suitable for utilization in PON transmission systems with per-channel data rates from $10 \mathrm{Gbit} / \mathrm{s}$ to $40 \mathrm{Gbit} / \mathrm{s}$ are chosen. The options of the utilization of mixed solutions are also evaluated. The aim of the Thesis, as well as tasks, novel achievements, statements to defend and main conclusions are summarized at the end of the chapter.

Chapter 2 proposes the initial evaluation of the utilization of data modulation formats using OptSim simulation software. Thus, the performance (bit-error-ratio (BER), maximal transmission distance) of several modulation formats is evaluated utilizing per-channel data rate of $10 \mathrm{Gbit} / \mathrm{s}$, as a result the modulation formats for further research are chosen. The feasibility of utilization of mixed solutions for the increase of the spectral efficiency of WDM-PON transmission system is also investigated.

Chapter 3 deals with a deeper evaluation of the previously chosen modulation formats utilizing per-channel data rates of $10 \mathrm{Gbit} / \mathrm{s}, 25 \mathrm{Gbit} / \mathrm{s}$ and $40 \mathrm{Gbit} / \mathrm{s}$ using academy and industry recognized VPI Design Suite simulation software. The analysis of the BER affecting factors for high data rate transmission (up to $40 \mathrm{Gbit} / \mathrm{s}$ ) is also performed. As a result the data modulation formats (NRZ-OOK and PAM-4, respectively) are chosen for the per-channel data rates of 10 Gbit/s and $25 \mathrm{Gbit} / \mathrm{s}$ for mixed $10 \mathrm{Gbit} / \mathrm{s}$ to $25 \mathrm{Gbit} / \mathrm{s}$ WDM-PON transmission system, where transmission of all (also $25 \mathrm{Gbit} / \mathrm{s}$ ) channels is ensured by the transmitters and receivers intended for the $10 \mathrm{Gbit} / \mathrm{s}$ transmission.

Chapter 4 deals with the analysis of the impact of the amplitude-frequency-response (AFR) of the transmitter on BER demonstrated by 25 Gbit/s (PAM-4) WDM-PON transmission system, as a result the approach for the modelling of AFR (using Matlab) is proposed and evaluated. The model of the mixed WR-WDM-PON transmission system in VPI Design Suite software with the calculation of AFR in Matlab software is developed. In the chapter, the experimental realization of the one-channel $25 \mathrm{Gbit} / \mathrm{s}$ (PAM-4) fiber optical transmission system as well as its modelling utilizing VPI Design Suite software is performed. As a result, the additional performance affecting factors were determined as well as the model developed in VPI Design Suite software was updated. At the end of the chapter, the values of MachZehnder amplitude-frequency-response, chromatic dispersion and pulse rise time, as well as the limits for minimum received optical signal power and thermal noise of the receiver are determined for the ensuring of the BER smaller than $1 \times 10^{-3}$ for $25 \mathrm{Gbit} / \mathrm{s}$ channels in the mixed 12.5 Gbit/s (NRZ) and 25 Gbit/s (PAM-4) WR-WDM-PON transmission system.

At the end of the Thesis the main conclusions are summarized and the directions for further research are proposed. 


\section{SUMMARIES OF CHAPTERS OF THE DOCTORAL THESIS}

\section{Chapter 1}

In Chapter 1, the technology for the realization of NGA solution is chosen, as well as theoretical evaluation of data modulation formats and assessment of the topicality of mixed solutions is performed.

In the introductory part, the theoretical analysis of the advantages, results of technoeconomical evaluation performed in "European FP7 OASE Integrated Project" were analyzed as well as the comparative analysis of the utilization of the technologies was performed to choose among two FTTH technologies - PON and active optical network (AON). During the comparative analysis, based on the statistical data about the percentage of the households connected to the FTTH/B network before February of 2017 [12], the countries (Latvia, Sweden, Lithuania, Norway, Bulgaria, Portugal, Spain, Belorussia, Estonia, Denmark, Slovenia, the Netherlands and Hungary) with the number of connections higher than $15 \%$ and with available information about FTTH technology were chosen. As a result, by analyzing the utilization of PON and AON in these countries [8], [11], [20], [36], [43], it was investigated that AON architecture is used in 6 of the 13 countries, while PON architecture - in 10 of the 13 considered countries (also in Latvia). Based on that, it was concluded that there are higher demands on PON architecture and, consequently, it is more topical in comparison to AON.

In Subchapter 1.1, the analysis of the development of the PON technologies (TDM-PON, wavelength-selected WDM-PON - WS-WDM-PON), WR-WDM-PON, time wavelength division multiplexed PON - TWDM-PON) was performed. As a result, it was concluded that the TWDM-PON is a cost-effective solution for realization of NG-PON2 in near future, while WDM-PON technology, that ensures the security and convergence is an advanced future solution for NGA networks. Moreover, the WR-WDM-PON is the most appropriate technology for long-term future solutions (future fiber optical access systems - FOAS), considering the best security and power budget.

In Subchapter 1.2, the utilization of modulation formats in fiber optical access systems with per-channel data rate from $10 \mathrm{Gbit} / \mathrm{s}$ to $40 \mathrm{Gbit} / \mathrm{s}$ was analyzed as a result it was concluded that for all bitrates $(10 \mathrm{Gbit} / \mathrm{s}, 25 \mathrm{Gbit} / \mathrm{s}$ and $40 \mathrm{Gbit} / \mathrm{s})$ it is not possible to choose the most appropriate modulation formats based on the already existing studies, because it is necessary to evaluate the suitability of each data modulation format for the determined solution (with certain requirements). By analyzing the features, possibilities of the realization as well as results of the previous studies (e.g. in [1], [2], [20], [21], [23], [30]-[32], [35]) about the considered data modulation formats (NRZ-OOK, DB, RZ-OOK, CRZ-OOK, CSRZ-OOK, NRZ-DPSK, RZDPSK, CSRZ-DPSK, NRZ-DQPSK, RZ-DQPSK and PAM-4) the following data modulation formats were chosen for further evaluation in the Thesis: NRZ-OOK, DB, RZ-OOK, CSRZOOK, NRZ-DPSK, RZ-DPSK, CSRZ-DPSK and PAM-4.

Subchapter 1.3 deals with the analysis of the utilization of mixed line rate (MLR) and multiple modulation format (MMF) solutions, as well as mixed solution with unequal channel spacing solution. As a result, it was concluded that mixed solutions are topical for all PON architectures (TWDM-PON, WS-WDM-PON and WR-WDM-PON). It means that for all 
architectures (WR-WDM-PON, TWDM-PON and WS-WDM-PON) mixed solutions can be considered for the enhancement of the spectral efficiency as well as cost-efficiency in the case of unequal data traffic. In addition, for TWDM-PON and WS-WDM-PON architectures the ensuring of coexistence as well as standard migration is necessary, while for WR-WDM-PON architecture - for ensuring open access.

\section{Chapter 2}

The mathematical models of the elements as well as the methods of the estimation of the signal quality were analyzed in Subchapters 2.1 and 2.2 of the Thesis. Subchapter 2.3 deals with the evaluation of seven data modulation formats (NRZ-OOK, DB, RZ-OOK, CSRZ-OOK, NRZ-DPSK, RZ-DPSK un CSRZ-DPSK) for two configurations of the transmission line utilizing the 16-channel WR-WDM-PON transmission system with $10 \mathrm{Gbit} / \mathrm{s}$ per-channel data rates (Fig. 2.1). It is worth noting that during the evaluation of the mixed solutions in Subchapter 2.4 , the bitrate of the part of the channels was increased to $40 \mathrm{Gbit} / \mathrm{s}$.

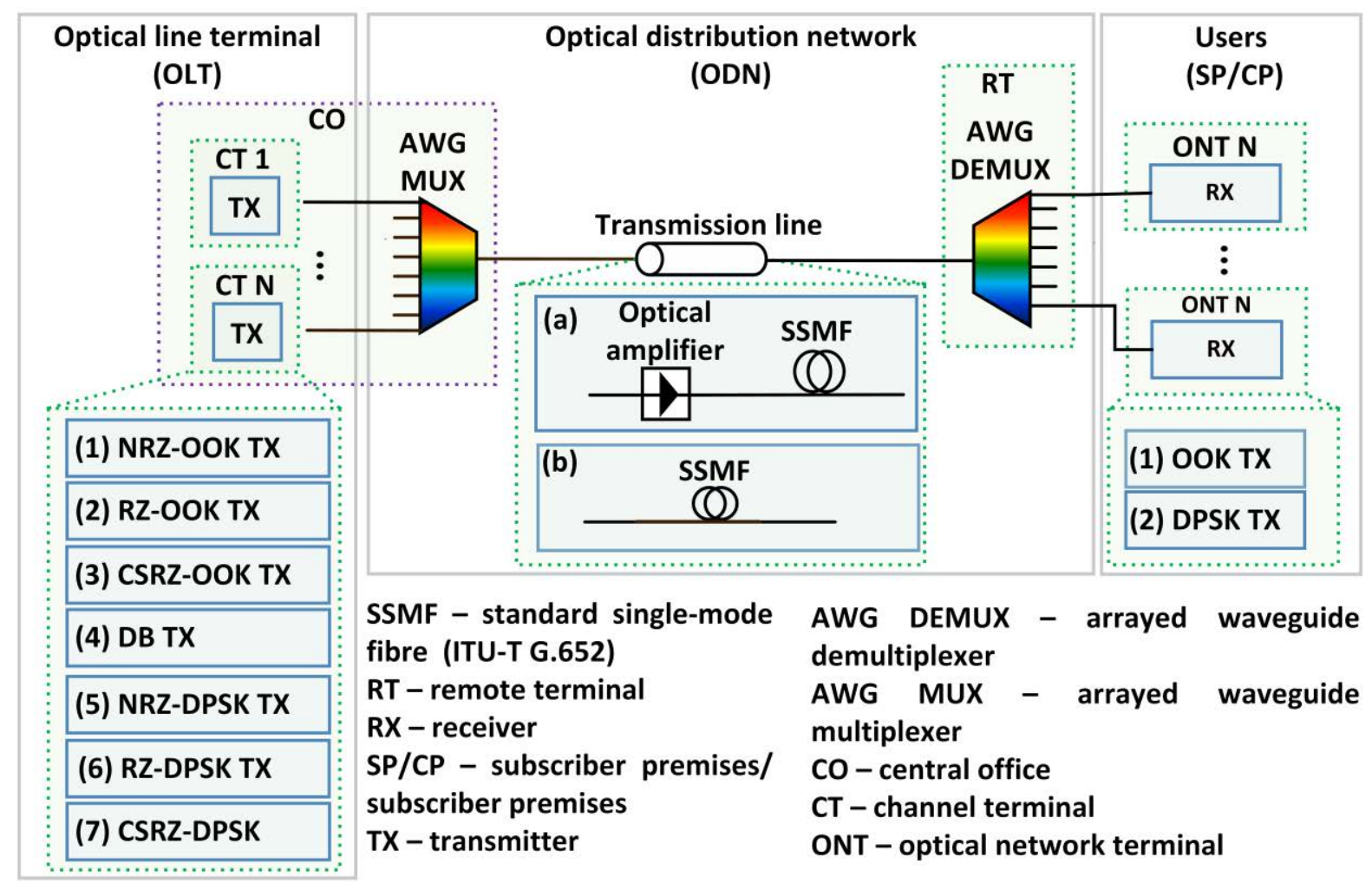

Fig. 2. The structure of the modelled WDM-PON transmission system in OptSim software.

At the beginning of the research, the BER dependence on transmission distance (Fig. 3) as well as maximum transmission distance with BER that does not exceed $1 \times 10^{-9}$ (Table 1 ) was determined for the considered modulation formats ensuring the same fiber input power (+16 dBm). 


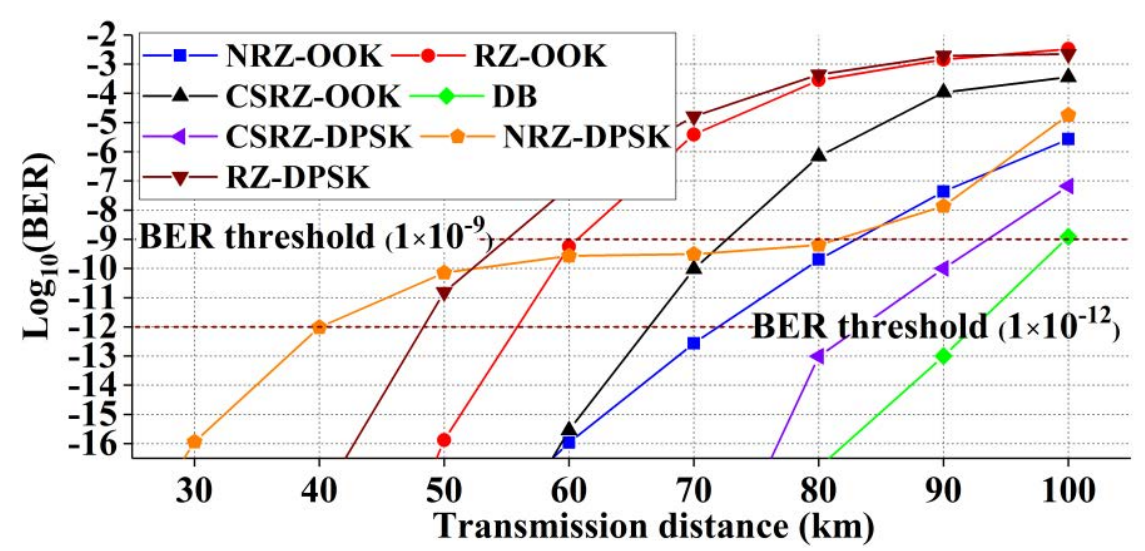

Fig. 3. BER dependence on the transmission distance for NRZ-OOK, RZ-OOK, CSRZ-OOK, DB, CSRZ-DPSK, NRZ-DPSK, RZ-DPSK modulation formats with the same fiber input power.

As a result, three of the modulation formats were chosen for further research - NRZ-OOK, that is traditionally utilized and has the simplest technical realization, DB and CSRZ-DPSK, which in comparison with NRZ-OOK have ensured the smallest BER (Fig. 3) and longest transmission distance (Table 1).

Table 1

Maximum Transmission Distance with BER $=1 \times 10^{-9}$ for the Investigated Modulation

Formats

\begin{tabular}{|c|c|}
\hline Modulation format & Maximum transmission distance with BER of $\mathbf{1} \times \mathbf{1 0}^{-\mathbf{9}}, \mathbf{k m}$ \\
\hline DB & 99 \\
\hline CSRZ-DPSK & 92 \\
\hline NRZ-OOK & 82 \\
\hline NRZ-DPSK & 80 \\
\hline CSRZ-OOK & 72 \\
\hline RZ-OOK & 60 \\
\hline RZ-DPSK & 54 \\
\hline
\end{tabular}

During next research, maximum transmission distance with BER that does not exceed $1 \times 10^{-12}$ was defined for the chosen modulation formats. It is important to mention, that during this research the necessary laser output power was adjusted for each data modulation format (Table 2).

As one can see from Table 2, in current research the longest transmission distance was also ensured by DB modulation format. It is worth mentioning that, although the transmission distance ensured by CSRZ-DPSK was longer than the ensured by NRZ, the technical implementation of CSRZ-DPSK was considerably more complicated and consequently (considering that DB performance was better than the performance of CSRZ-DPSK), CSRZDPSK was not utilized in further research. To sum up, it was concluded that for $10 \mathrm{Gbit} / \mathbf{s}$ data rate the most appropriate modulation formats are NRZ-OOK (easiest to implement) and DB (ensures the smallest BER, longest transmission distance). 
Maximum Transmission Distance with BER $=1 \times 10^{-12}$ for the Investigated Modulation Formats

\begin{tabular}{|c|c|c|}
\hline Modulation format & $\begin{array}{c}\text { Maximum transmission } \\
\text { distance with BER of } \mathbf{1} \times \mathbf{1 0}^{\mathbf{- 1 2}}, \\
\mathbf{~ k m}\end{array}$ & $\begin{array}{c}\text { Laser output power, } \\
\mathbf{d B m}\end{array}$ \\
\hline DB & 100 & $+15,5$ \\
\hline CSRZ-DPSK & 80 & +11 \\
\hline NRZ-OOK & 70 & +11 \\
\hline
\end{tabular}

Considering the assessment of the mixed solutions for the increase of the spectral efficiency of the 16-channel WDM-PON transmission system with per-channel data rate of $10 \mathrm{Gbit} / \mathrm{s}$, that was performed in Subchapter 2.4, it was concluded that in 16-channell NRZ-OOK modulated WDM-PON transmission system half of the channels would be substituted with DB-modulated channels with data rate of $40 \mathrm{Gbit} / \mathrm{s}$, it is possible not only to maintain the quality (Q-factor higher than $18.3 \mathrm{~dB}$ ) of the basic (10 Gbit/s NRZ-OOK) channels, but also to increase the quality of the signals transmitted in spectrally efficient DB-modulated channels (with higher data rate and/or smaller channel spacing.

When analyzing the spectral efficiency of 16 channel WDM-PON transmission system, it is possible to conclude that the utilization of mixed solutions is not the most effective way for increasing the spectral efficiency of the considered WDM-PON. It means that by ensuring the same signal quality for all the channels ( $\mathrm{Q}$ factor $>16.95 \mathrm{~dB}$, accordingly BER $<1 \times 10^{-12}$ ) the highest spectral efficiency (equal to $0.61(\mathrm{bit} / \mathrm{s}) / \mathrm{Hz}$ ) for the considered 16 channel WDMPON transmission system is ensured by utilizing for all of the channels NRZ-OOK modulation format with data rate of $10 \mathrm{Gbit} / \mathrm{s}$ and channel spacing of $18.75 \mathrm{GHz}$. To compare, by utilization of MLR with MMF and unequal channel spacing in the considered 16 channel WDM-PON transmission system it is possible to ensure spectral efficiency up to 0.51 (bit/s)/Hz if the unequal channel spacing is utilized, and up to 0.27 (bit/s)/Hz if only MLR with MMF solution is utilized. It is important to mention that it is necessary to utilize the electrical and optical filters with properly chosen bandwidths that makes the technical realization of this solution complicated. Moreover, in this case, the increase of the spectral efficiency means the possibility to increase the capacity of the transmission system by increasing the number of the channels, which means significant expenses. Consequently, the mixed MLR and MMF solution remains topical, as it not only ensures the increase of the spectral efficiency but is also suitable in the case of the unequal data traffic as well as for ensuring of the coexistence, migration and open access.

\section{Chapter 3}

The simulation setup utilized in the Chapter 3 of the Thesis is shown in Fig. 4. It is important to mention that all further research in the Thesis is performed utilizing VPIphotonics Design Suite simulation software that ensures the wider possibilities in comparison with the 
OptSim software that was used previously. The analysis of mathematical models of the elements available in VPIphotonics Design Suite as well as the analysis of the signal simulation and quality assessment methods was performed in Subchapter 3.1, whereas Subchapter 3.2 deals with the evaluation of the performance affecting factors for the DB and PAM-4 modulated WDM-PON transmission system with per-channel data rates of $40 \mathrm{Gbit} / \mathrm{s}$, as a result the following conclusions were made:

- when evaluating the factors that affect the signal transmission in the optical fiber (dispersion, nonlinear effects) for WDM-PON transmission system with data rate of $40 \mathrm{Gbit} / \mathrm{s}$, the main BER affecting factor is chromatic dispersion in both frequency bands $\mathrm{C}$ and $\mathrm{L}$ (for both, PAM-4 and DB, modulation formats);

- when evaluating the impact of the parameters of the transmission system (relative intensity noise (RIN) of the laser, side-mode suppression ratio of the laser (SMSR), -3 $\mathrm{dB}$ bandwidth and amplitude-frequency response of the modulator, dispersion and nonlinear coefficient of the fiber, as well as the responsivity, dark current, thermal and shot noise of the receiver, it was concluded that for WDM-PON transmission system with per-channel data rate of $40 \mathrm{Gbit} / \mathrm{s}$ the main performance affecting factor is frequency response of the transmitter.

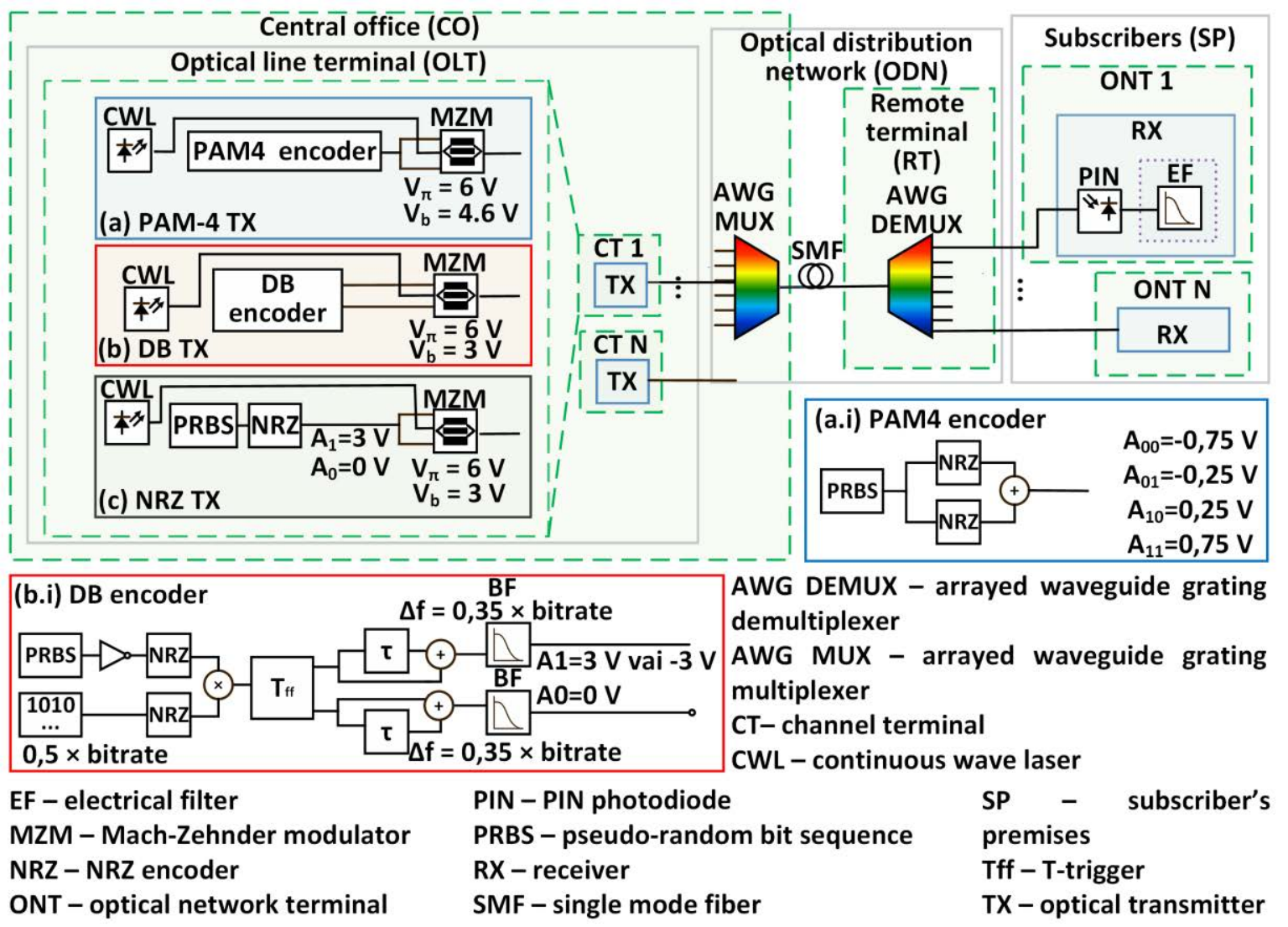

Fig. 4. The structure of the WDM-PON transmission system developed and simulated in VPIphotonics Design Suite software. 
The evaluation of the modulation formats is continued in Subchapter 3.3. DB and NRZOOK data modulation formats (considering previous results) as well as PAM-4 modulation format (chosen based on the recent studies, e.g. in [23], [30]-[33], were compared utilizing data per-channel rates of $10 \mathrm{Gbit} / \mathrm{s}, 25 \mathrm{Gbit} / \mathrm{s}$ and $40 \mathrm{Gbit} / \mathrm{s}$.

Based on the results of the evaluation with per-channel data rate of $10 \mathrm{Gbit} / \mathrm{s}$ (Fig. 5), it was observed that BER ensured by PAM-4 is higher than the one ensured by NRZ-OOK and DB.

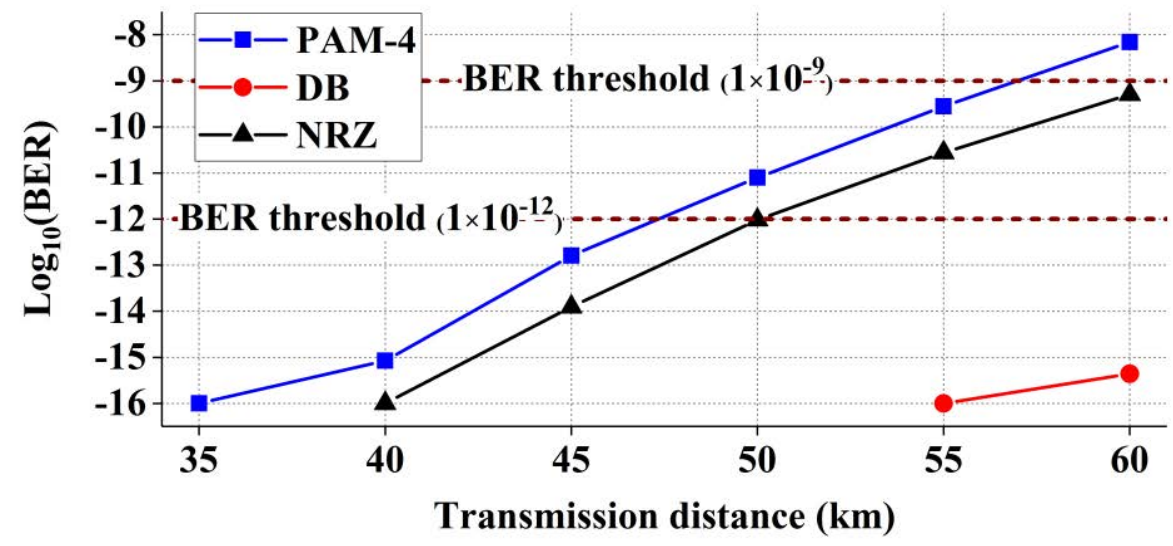

Fig. 5. BER dependence on transmission distance of DB, PAM-4 and NRZ modulated WDM-PON transmission system with data rate of $10 \mathrm{Gbit} / \mathrm{s}$.

This means that the BER ensured at all considered transmission distances (from $35 \mathrm{~km}$ to $60 \mathrm{~km}$ ) is by one power higher than the one ensured by NRZ-OOK, while the technical implementation of PAM-4 is more complicated in comparison to NRZ-OOK (Fig. 4), consequently, the utilization of PAM-4 with the data rate of $10 \mathrm{Gbit} / \mathrm{s}$ is not reasonable.

While utilizing data rates of $25 \mathrm{Gbit} / \mathrm{s}$ and $40 \mathrm{Gbit} / \mathrm{s}$ (Fig. 6), it was observed that the transmission distance ensured by NRZ-OOK is about two times smaller than the transmission distance that it is necessary to ensure utilization of PAM-4 and DB, consequently, it was concluded that for data rates above $25 \mathrm{Gbit} / \mathrm{s}$ it is necessary to substitute NRZ-OOK with another data modulation format, if it is necessary to ensure transmission distances higher than $5 \mathrm{~km}$ with data rate of $40 \mathrm{Gbit} / \mathrm{s}$, or higher than $15 \mathrm{~km}$ with data rate higher than $25 \mathrm{Gbit} / \mathrm{s}$. It is important to mention, that utilizing data rate of $40 \mathrm{Gbit} / \mathrm{s}$ none of the considered data modulation formats was capable to ensure the transmission distance longer than $12 \mathrm{~km}$, while the minimum transmission distance required in ITU-T G. 989.2 recommendation is $20 \mathrm{~km}$ [16]. Consequently, only the data rate of $25 \mathrm{Gbit} / \mathrm{s}$ was utilized in further research.

During further research (Subchapter 3.4), DB and PAM-4 modulation formats were compared by evaluating the impact of the $-3 \mathrm{~dB}$ bandwidth of the transmitter and receiver with per-channel data rate of $25 \mathrm{Gbit} / \mathrm{s}$ (Table 3). 


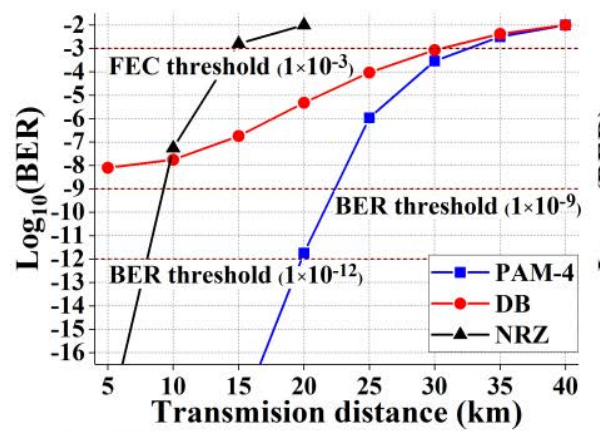

(a) $25 \mathrm{Gbit} / \mathrm{s}$

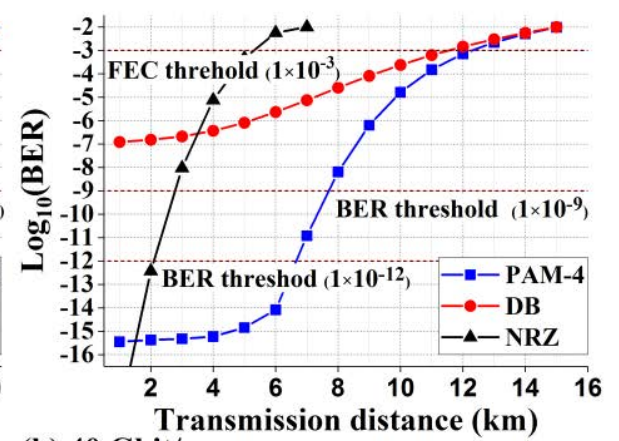

(b) 40 Gbit/s

Fig. 6. DB, PAM-4 and NRZ BER dependence on transmission distance of DB, PAM-4 and NRZ modulated WDM-PON transmission system with data rate of (a) 25 Gbit/s and (b) 40 Gbit/s.

Table 3

The Comparison of PAM-4 and DB Modulation Formats with Data Rate of 25 Gbit/s

\begin{tabular}{|c|c|c|c|c|c|}
\hline \multirow{3}{*}{$\begin{array}{c}-\mathbf{3} \mathrm{dB} \\
\text { bandwidth of } \\
\text { the } \\
\text { transmitter, } \\
\text { GHz }\end{array}$} & \multirow{3}{*}{$\begin{array}{c}-3 \mathrm{~dB} \text { bandwidth } \\
\text { of the receiver, } \\
\mathbf{G H z}\end{array}$} & \multicolumn{4}{|c|}{$\begin{array}{l}\text { Minimum received optical signal power, } \mathrm{dBm} \\
\left(\text { for } \mathrm{BER} \leq \mathbf{1 0}^{-3}\right)\end{array}$} \\
\hline & & \multicolumn{2}{|c|}{$100 \mathrm{GHz}$} & \multicolumn{2}{|c|}{$50 \mathrm{GHz}$} \\
\hline & & PAM-4 & DB & PAM-4 & DB \\
\hline 20 & 20 & -12.5 & -16 & -12 & -8 \\
\hline 20 & 10 & -13 & - & -12.5 & - \\
\hline 12 & 20 & -11 & -14.5 & -11 & - \\
\hline 12 & 10 & -11 & - & -9.5 & - \\
\hline
\end{tabular}

Considering the results shown in Table 3, the following conclusion of the Thesis was drawn: it is possible to utilize the transmitters and receivers intended for the transmission with $10 \mathrm{Gbit} / \mathrm{s}$ data rate in WDM-PON transmission system with $25 \mathrm{Gbit} / \mathrm{s}$ per-channel data transmission rate as well as to ensure channel spacing of $50 \mathrm{GHz}$ if the PAM-4 modulation format is utilized, whereas utilizing DB modulation format with transmitters and receivers intended for $20 \mathrm{Gbit} / \mathrm{s}$ data transmission rate and $100 \mathrm{GHz}$ channel spacing, it is possible to ensure BER below $1 \times 10^{-3}$ with 3 dB smaller received optical signal power (in comparison to PAM-4).

\section{Chapter 4}

In Subchapter 4.1, suitable modulation formats (NRZ, DB or PAM-4), transmitters and receivers (intended for $10 \mathrm{Gbit} / \mathrm{s}(10 \mathrm{G})$ or $20 \mathrm{Gbit} / \mathrm{s}$ data rate $(20 \mathrm{G})$ ), as well as the transmission distance for the development of the mixed solution were chosen. That was done by evaluating BER ensured by corresponding data modulation formats utilizing different data rates, as well as different transmitters and receivers and transmission distances defined in ITU-T G.989.2 recommendation [16] - $20 \mathrm{~km}, 40 \mathrm{~km}$ and $60 \mathrm{~km}$ (Table 4). 
BER of the Worst Channel in 8 Channel WDM-PON with Different Data Rates, Transmission Distances, and Transmitters and Receivers

\begin{tabular}{|c|c|c|c|c|c|}
\hline Data rate & Transmitter & Receiver & $\begin{array}{l}\text { Distance, } \\
\mathbf{k m}\end{array}$ & $\begin{array}{c}\text { Modulation } \\
\text { format }\end{array}$ & $\begin{array}{c}\text { BER of the worst } \\
\text { channel }\end{array}$ \\
\hline \multirow{6}{*}{10 Gbit/s } & \multirow{6}{*}{$10 \mathrm{G}$} & \multirow{6}{*}{$10 \mathrm{G}$} & \multirow{2}{*}{20} & NRZ & $1.8 \times 10^{-27}$ \\
\hline & & & & DB & $2.0 \times 10^{-38}$ \\
\hline & & & \multirow{2}{*}{40} & NRZ & $5.9 \times 10^{-10}$ \\
\hline & & & & DB & $1.0 \times 10^{-29}$ \\
\hline & & & \multirow{2}{*}{60} & NRZ & $5.3 \times 10^{-8}$ \\
\hline & & & & DB & $3.0 \times 10^{-20}$ \\
\hline \multirow{2}{*}{$25 \mathrm{Gbit} / \mathrm{s}$} & \multirow{2}{*}{$20 \mathrm{G}$} & \multirow{2}{*}{$20 \mathrm{G}$} & 20 & \multirow{2}{*}{ DB } & $2.9 \times 10^{-7}$ \\
\hline & & & 40 & & $1.1 \times 10^{-2}$ \\
\hline \multirow{2}{*}{$25 \mathrm{Gbit} / \mathrm{s}$} & \multirow{2}{*}{$20 \mathrm{G}$} & \multirow{2}{*}{$10 \mathrm{G}$} & 20 & \multirow{2}{*}{ PAM-4 } & $4.1 \times 10^{-14}$ \\
\hline & & & 40 & & $1.1 \times 10^{-2}$ \\
\hline \multirow{2}{*}{$25 \mathrm{Gbit} / \mathrm{s}$} & \multirow{2}{*}{$10 \mathrm{G}$} & \multirow{2}{*}{$10 \mathrm{G}$} & 20 & \multirow{2}{*}{ PAM4 } & $2.8 \times 10^{-11}$ \\
\hline & & & 40 & & $1.29 \times 10^{-2}$ \\
\hline
\end{tabular}

As one can see in Table 4, only utilizing the transmission distance of $\mathbf{2 0} \mathbf{~} \mathbf{~ m}$ it is possible to ensure transmission with data rates of $25 \mathrm{Gbit} / \mathrm{s}$. Whereas for the transmission distance of $20 \mathbf{~ k m}$ with data rate of $\mathbf{1 0} \mathbf{~ G b i t / s}$ both, NRZ-OOK and DB, ensure very small BER (considerably smaller than $1 \times 10^{-16}$ ), consequently, in this case it is necessary to utilize NRZOOK that has simpler technical implementation. In turn, for the data rate of $25 \mathbf{~ G b i t / s}$ it is necessary to utilize PAM-4 modulation format because it ensures significantly smaller BER (up to six BER powers) in comparison with DB. Considering that utilizing 10G transmitters, BER ensured by PAM-4 $\left(2.8 \times 10^{-11}\right)$ is considerably smaller than the threshold of forward error correction $\left(\right.$ FEC) threshold $\left(1 \times 10^{-3}\right)$, it was decided to ensure the utilization of transmitters and receivers intended for the $10 \mathrm{Gbit} / \mathrm{s}$ data rate for the transmission in all of the channels of the mixed solution (also with data rate of $25 \mathrm{Gbit} / \mathrm{s}$ ). It is important to mention that the bandwidth of the transmitter and receiver influences the cost of the transmission system significantly [41].

Considering the difference that was observed among the BER values that were ensured, correspondingly, by utilizing 4-pole Bessel filter for the emulation of the frequency response of the transmitter and by utilizing frequency response of the real Mach-Zehnder modulator (MZM) from the technical specification [18] (Fig. 7), Subchapter 4.2 of the Thesis deals with the analysis of the impact of transmitter amplitude-frequency response on the obtained BER. 


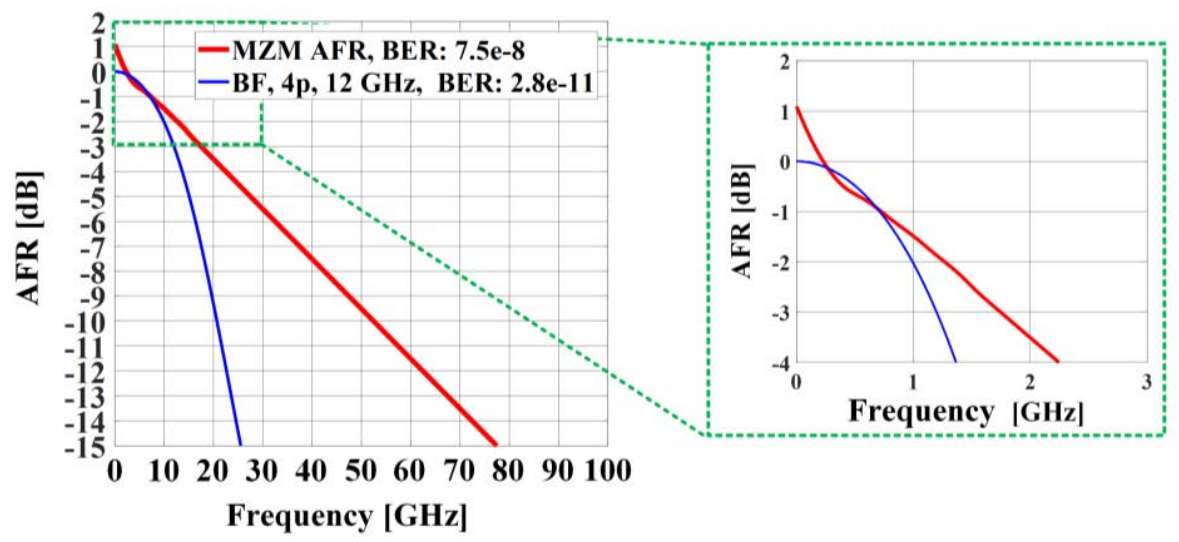

Fig. 6. AFR of MZM from technical specification [18] (red) and AFR of $12 \mathrm{GHz}, 4$ pole Bessel filter (blue).

At the beginning, BER was evaluated utilizing different analytical filters (1-pole Bessel (1 p. BF), 4-pole Bessel (4 p. BF), 1-pole Gaussian (1 p. GF) and 4-pole Gaussian (4 p. GF)) (see Fig. 7). As a result, it was observed that the smallest of the ensured BER values was observed for 4-pole Gaussian filter with the bandwidth of $10 \mathrm{GHz}$, while, with the increase of the bandwidth, the type of the filter that ensures the smallest BER (for fixed bandwidth) is changing.

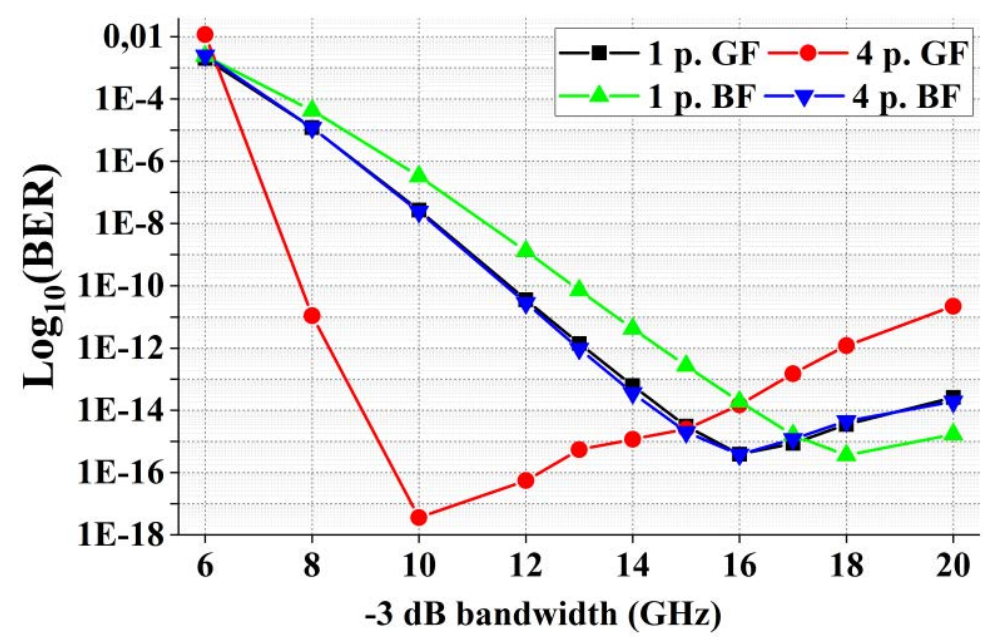

Fig. 7. BER dependence on $-3 \mathrm{~dB}$ bandwidth utilizing AFR of the different types of filters.

Considering the mentioned observations, three points were chosen for further investigation: $10 \mathrm{GHz}$ (with the smallest possible BER), $15 \mathrm{GHz}$ (BER demonstrated by three filters is similar), and $18 \mathrm{GHz}$ (the smallest BER is ensured by 1-pole Bessel filter, which before demonstrated the highest BER). The shapes of AFRs of the corresponding filters were analyzed in corresponding points, as a result, it was concluded that it is necessary to keep unchanged the spectrum of the signal before $10 \mathrm{GHz}$, whereas from $10 \mathrm{GHz}$ to $15 \mathrm{GHz}$ it is necessary to filter the spectrum as much as possible.

Consequently, when modelling the amplitude-frequency-response of the transmitter in PAM-4 modulated WDM-PON with per-channel data rate of $25 \mathrm{Gbit} / \mathrm{s}$, it is important to define not only the $-3 \mathrm{~dB}$ bandwidth of AFR, but also the parameters that define the shape of AFR at 
low frequencies. By summarizing the values of $-3 \mathrm{~dB}$ and $-1 \mathrm{~dB}$ bandwidths of AFR for ensuring the smallest BER for each type of the filter, it was observed, that for each type of the filter the smallest BER is ensured with the similar value of $-1 \mathrm{~dB}$ bandwidth (near $9 \mathrm{GHz}$ ). Consequently, the $\mathbf{- 1} \mathbf{~ d B}$ bandwidth was chosen as a point that characterizes the shape of frequency response of the transmitter at low frequencies.

It is important to mention that the impact of the AFR hop near $0 \mathrm{~Hz}$, that is observed on the AFR from technical specification [18] (red curve in Fig. 6) was also evaluated. As a result, it was investigated that the impact of the hop of AFR is significant (up to five BER powers). Respectively, if the hop is taken off, the ensured BER decreases from $7.5 \times 10^{-8}$ to $2.8 \times 10^{-11}$. It is worth mentioning that according to [5], the anomalies (such as significant hop, fluctuations) in AFR of $\mathrm{LiNbO}_{3} \mathrm{MZM}$ at low frequencies (up to $1 \mathrm{GHz}$ ) are frequently observed. Authors in [5] explain these anomalies by the properties of $\mathrm{LiNbO}_{3}$ crystal and mention several possible reasons, such as the differences in distribution of voltages between modulator layers (the impact is observed at frequencies below $\sim 1 \mathrm{MHz}$ ), acoustical effects (below $1 \mathrm{GHz}$ ), as well as the change of the crystal properties with the increase of the frequency (the impact is observed below $100 \mathrm{MHz}$ ) [5]. Consequently, it was concluded, that while modelling AFR of the MZM, it is necessary also to consider one more point - around $\mathbf{0 ~} \mathbf{H z}$.

Subchapter 4.3 of the Thesis deals with the development and evaluation of the initial model of mixed $25 \mathrm{Gbit} / \mathrm{s}$ (PAM-4), $12.5 \mathrm{Gbit} / \mathrm{s}$ (NRZ) resolution. It is important to mention that for the channels with a smaller data rate (NRZ-modulated) the data rate of $12.5 \mathrm{Gbit} / \mathrm{s}$ was chosen instead of $10 \mathrm{Gbit} / \mathrm{s}$. It was done considering that even now the data rates higher than $10 \mathrm{Gbit} / \mathrm{s}$ (e.g. $10.709 \mathrm{Gbit} / \mathrm{s}, 11.09 \mathrm{Gbit} / \mathrm{s}, 10.3125 \mathrm{Gbit} / \mathrm{s}, 10.1376 \mathrm{Gbit} / \mathrm{s}$ ) are present in ITU-T G.989.2 recommendation [17], while data rate of $12.5 \mathrm{Gbit} / \mathrm{s}$ in the proposed mixed solution is especially promising in the context of technical realization owing to the scalability. Thus the $25 \mathrm{Gbit} / \mathrm{s}$ PAM-4 modulated signal is obtained combining two NRZ-OOK channels with data rate of 12.5 Gbit/s. It is worth mentioning that in such a way also efficiency of the simulation is ensured. It is also important, that the BER difference that was observed with the increase of data rate from $10 \mathrm{Gbit} / \mathrm{s}$ to $12.5 \mathrm{Gbit} / \mathrm{s}$ was not significant (not higher than BER power).

Based on the results described in Subchapter 4.3, it was concluded that the utilization of concept of the mixed solutions, as well as the decrease of the channel spacing to $50 \mathrm{GHz}$ does not influence the performance (BER minimum received signal power) significantly (not more than one BER power or $1 \mathrm{~dB}$ ). Consequently, the aim of further research was to investigate the transmission of $25 \mathrm{Gbit} / \mathrm{s}$ PAM-4 channels.

In Subchapter 4.4, the AFR model proposed in Subchapter 4.2. was evaluated as well as the initial evaluation of the impact of AFR was performed. It is necessary to mention that the calculation of the AFR model was performed utilizing the developed Matlab program. At the beginning, based on the defined AFR values at $0 \mathrm{~Hz},-1 \mathrm{~dB}$ and $-3 \mathrm{~dB}$ points, the AFR up to $-3 \mathrm{~dB}$ level was calculated utilizing cubic interpolation [44]. Whereas the rest of the AFR was calculated assuming that further curve is linear (based on AFR from MZM technical specification [18]). As one can see in Fig. 8, the difference between BER obtained by utilizing the mentioned AFRs is not significant (not higher than one BER power). 


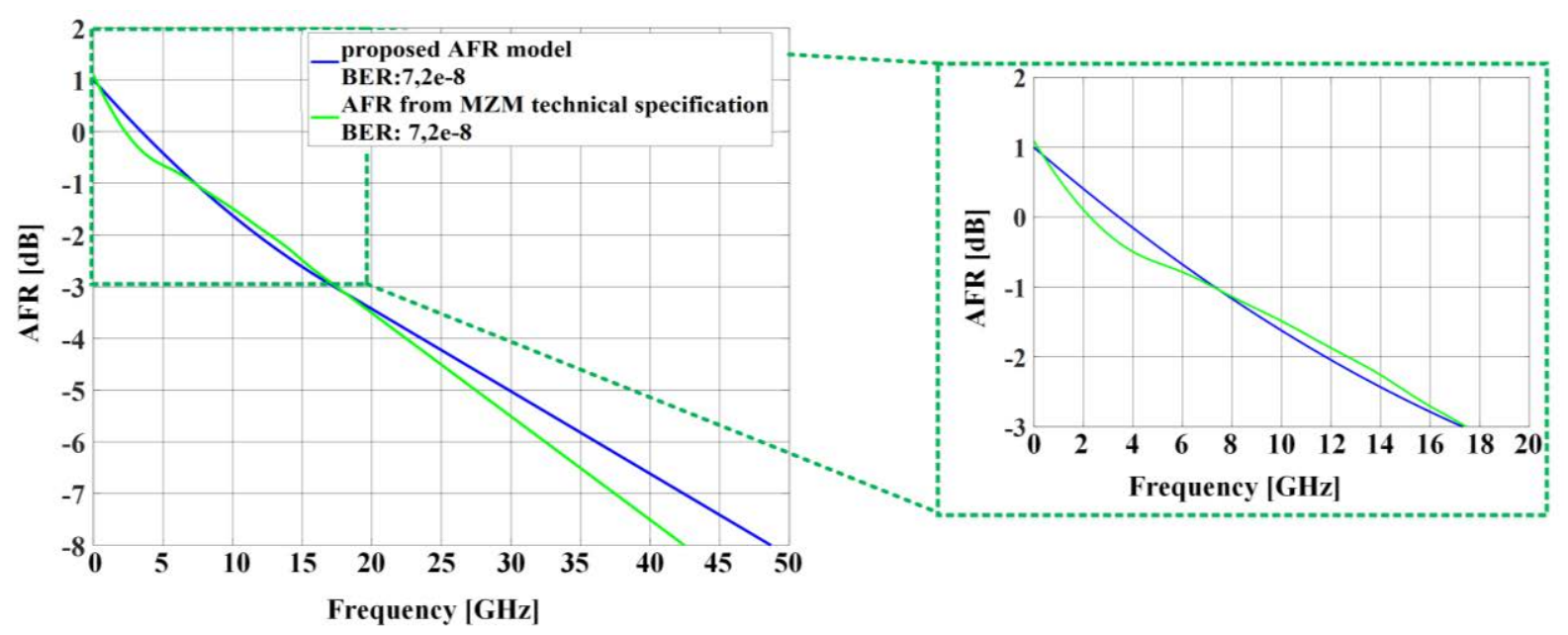

Fig 8. The comparison of the AFR model with the AFR from specification [18].

It is important to mention that in the scope of the Thesis AFR model was compared with the AFR from technical specification in different configurations of the transmission system (including mixed solution, different values of chromatic dispersion, pulse rise time, etc.) and in all of the cases difference in the obtained BER values was not higher than BER power.

While, during the initial evaluation of the impact of the AFR utilizing the described approach, the different AFR were modelled as a result the BER dependence on $-3 \mathrm{~dB}$ bandwidth for different values of the $-1 \mathrm{~dB}$ bandwidth were evaluated (with $100 \mathrm{GHz}$ and $50 \mathrm{GHz}$ channel spacing). It was investigated, that the minimal AFR values for the ensuring the transmission with BER smaller than $1 \times 10^{-3}$ do not depend on channel spacing. While comparing AFR with the hop up $0 \mathrm{~Hz}$ (was set equal to $+1 \mathrm{~dB}$ ) and without it, it was observed that minimal values of $-3 \mathrm{~dB}$ and $-1 \mathrm{~dB}$ bandwidths, that are required to ensure transmission with BER smaller then $1 \times 10^{-3}$, utilizing AFR with the hop, are by, correspondingly, $2 \mathrm{GHz}$ and $1 \mathrm{GHz}$ bigger in comparison with the utilization of AFR without hop. Consequently, in the further research AFR with the hop was evaluated as it corresponds to the worst case scenario. Moreover, AFR with the hop was observed also in the technical specification of the commercially available MZM [18].

In the 4.5. chapter one-channel $25 \mathrm{Gbit} / \mathrm{s}$ PAM-4 modulated transmission system (Fig. 9) was experimentally implemented in the Laboratory of the Fiber optical transmission systems of Institute of Telecommunications of Riga Technical University. 


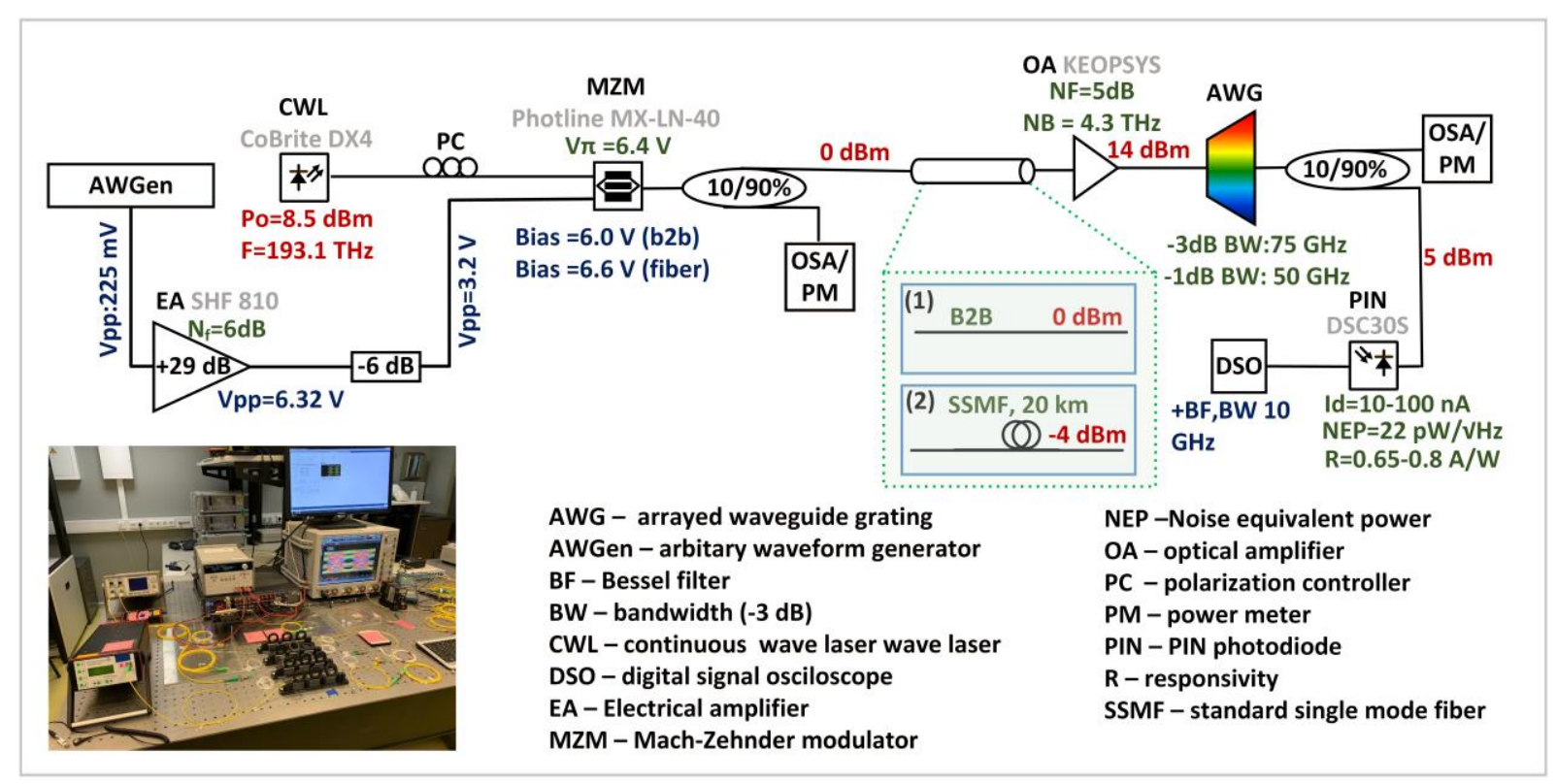

Fig. 9. One-channel experimental 25 Gbit/s PAM-4 modulated transmission system.

Considering that based on the results of the previous research, in the 25 Gbit/s PAM- 4 modulated transmission system the significant impact between channels is not observed as well as considering the availability of the equipment in the laboratory transmission system with one channel was realized. To apply the obtained results to WDM-PON the AWG (arrayed waveguide grating $-A W G$ ) demultiplexer with the channel spacing of $100 \mathrm{GHz}$ (with the same -3 and $-1 \mathrm{~dB}$ bandwidths as utilized during the simulations) was utilized in one-channel transmission system. Moreover, it is important to mention that the PIN photodiode available in laboratory is high-power, respectively, it supports the high-power input signal (up to $+16 \mathrm{dBm}$ ), while the minimal input power for it is also high (at least $+4 \mathrm{dBm}$ ), that is significantly higher than the sensitivity of the PIN photoreceivers suitable for PON solutions. Due to it, during the experiment EDFA (erbium dopped fiber amplifier) with the fixed output power of $14 \mathrm{dBm}$ was utilized. It is important to mention, that in the case if the suitable receiver would be available, EDFA would not be necessary. During the experiments the measurements for the two types of the transmission line - without fiber (Fig. 9, line (1)), as well as utilizing $20 \mathrm{~km}$ long optical fiber (Fig. 9, line (2)). During the experiment the matching of the modulator bias voltage as well as the bandwidth of the additional electrical filter was performed. As a result, during the transmission over $20 \mathrm{~km}$ long fiber, the biggest height of the eyes was ensured with the bias voltage of $6.6 \mathrm{~V}$ and Bessel filter of $10 \mathrm{GHz}$.

The BER measurements, utilizing the direct BER estimation available in Keysight digital oscilloscope were also performed. As a result, after the transmission of 53383284 bits over 20 $\mathrm{km}$ long fiber the errors were not observed. It is important to mention, that utilizing the method proposed in [41] it was determined, that minimal number of bits, that it is necessary to transmit without errors, to conclude with the confidence level (CL) of $99 \%$ that the BER of transmission system is smaller then determined BER value (in this case $1 \times 10^{-3}$ ) is 4605 bits (equation (1)). 


$$
N_{\text {bits }}=\frac{-\ln (1-C L)}{B E R}=\frac{-\ln (1-0.99)}{0.001}=4605 .
$$

Considering that the number of the bits transmitted without errors during the experiment is significantly higher, it can be concluded, that it is possible to experimentally ensure the transmission of $25 \mathrm{Gbit} / \mathrm{s}$ PAM-4 signal over $20 \mathrm{~km}$ with BER below $1 \times 10^{-3}$ threshold.

During the next phase of the research, the task to evaluate the proposed mixed WDM-PON model by comparing it with the results of the experiment was performed. Considering the significant differences (the are explained with the availability of the equipment) between the structure and elements of the experimental transmission system and proposed simulation model, it was decided to repeat the results of the experiment by adding additional elements to the model as well as by setting the parameters of the elements corresponding to ones utilized during the experiment (Fig. 10).

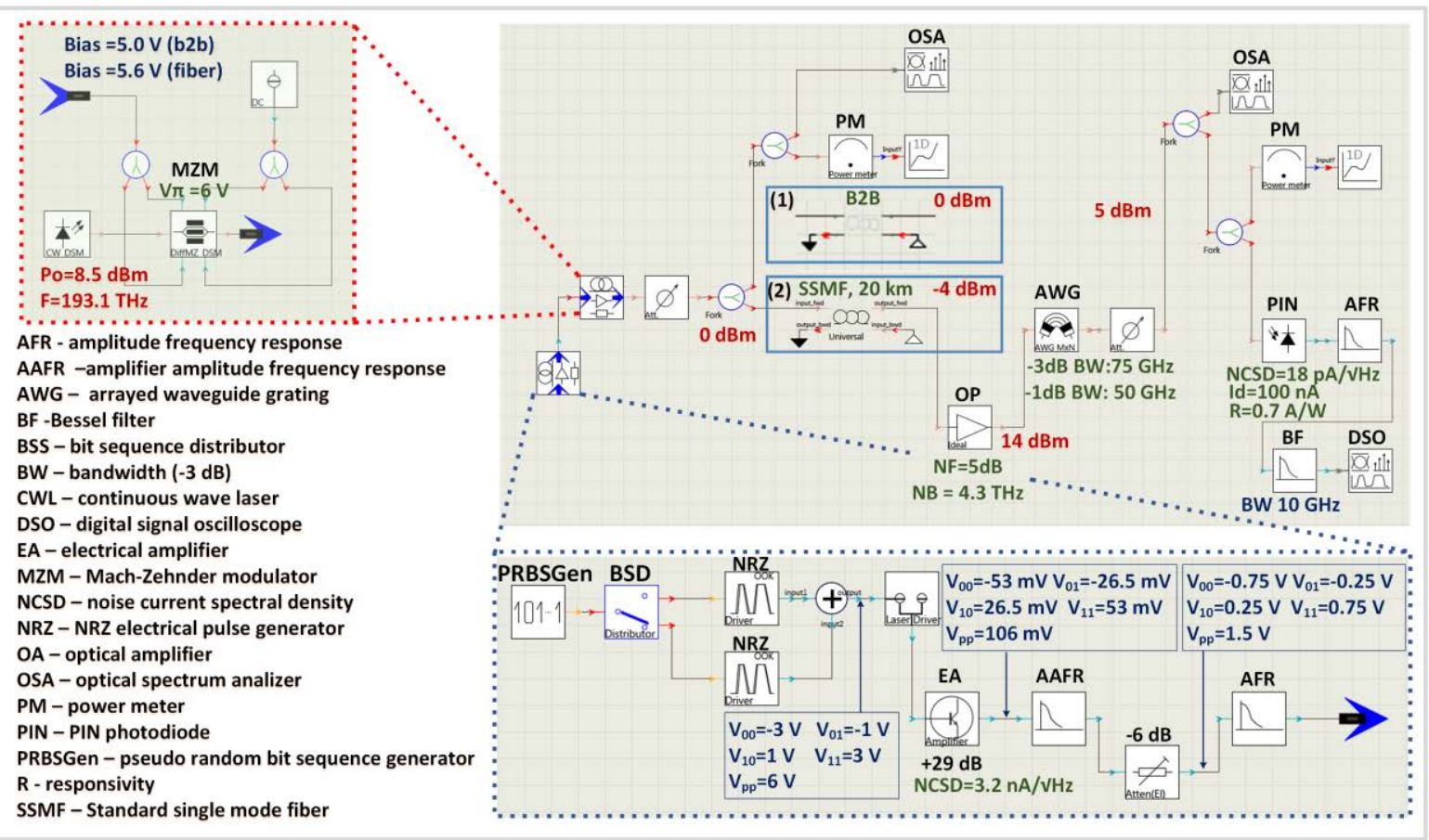

Fig.10. The model of the one-channel 25 Gbit/s PAM-4 modulated transmission system developed in VPI Design Suite software.

Thereby, it was evaluated, whether it is possible to obtained results close those obtained experimentally utilizing the model proposed in the thesis and based on the parameters available in the technical specifications. The quality of the signals in this case was evaluated utilizing the height of the eye diagrams, that experimentally was obtained utilizing Keysight digital signal oscilloscope. To compare experimental eye diagrams in volts with the eye diagrams in amperes obtained during the simulations, as well as to performed comparison without the dependence on the values of the current and voltage, the relative eye height (RAH) was utilized (RAA). That was defined based on the characteristic for two-level signal offered in [42], however in this case the peak-to-peak voltage defined by oscilloscope $\left(V_{\mathrm{pp}}\right)$ was considered as the 
amplitude of the signal, correspondingly, in the case of the simulations the $I_{\mathrm{pp}}$ current was utilized. The obtained eye diagrams are shown in Fig.11, while the values of the RAG are summarized in Table 5. It is important to mention, that to compare the results of the experiment and the simulation without the dependence on the uniformity of heights of the eyes, the additional characteristic - common relative height of the eyes was introduced. That was necessary to ensure correct comparison, because it is also possible to ensure more equal eyes (in comparison with the our experimentally obtained) in practice, for example in experimental demonstrations [7], [13], [14], [22], [26], [27], [34], by the adjusting of the driving process of the modulator.

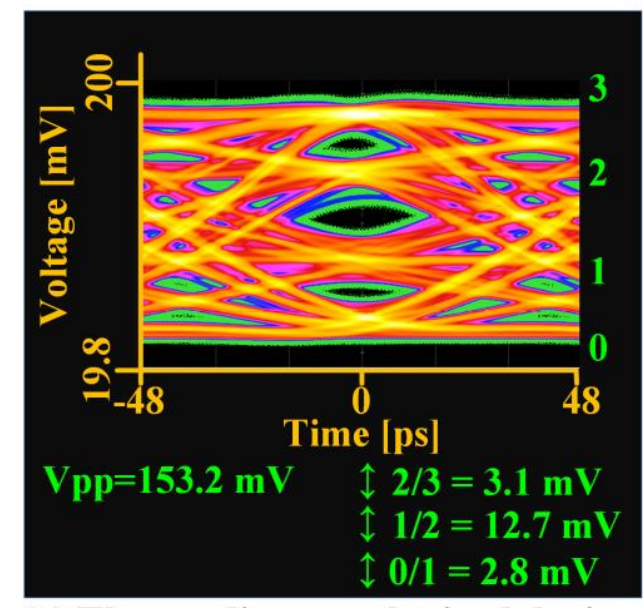

(a) The eye diagram obtained during the experiment

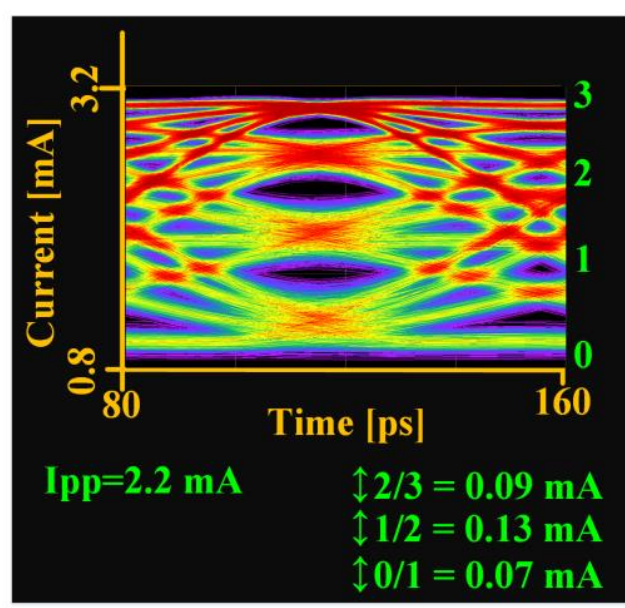

(b) The eye diagram obtained during the simulation

Fig.11. The eye diagrams of one-channel 25 Gbit/s PAM-4 modulated transmission system, that were obtained after transmission at $20 \mathrm{~km}$ during the (a) experiment and (b) simulation.

Table 5

The evaluation of eye heights of one-channel 25 Gbit/s PAM-4 modulated transmission system, that were obtained after transmission at $20 \mathrm{~km}$ during the experiment and simulation

\begin{tabular}{|c|c|c|c|c|}
\hline \multirow{2}{*}{ Eye } & \multicolumn{2}{|c|}{ Relative eye height, \% } & \multicolumn{2}{c|}{ Common relative height of the eyes, \% } \\
\cline { 2 - 3 } & Experiment & Simulation & Experiment & Simulation \\
\hline $2 / 3$ & 2.0 & 4.2 & \multirow{2}{*}{$\mathbf{1 2 . 1}$} & \multirow{1}{*}{$\mathbf{1 3 . 3}$} \\
\hline $1 / 2$ & 8.3 & 5.7 & & \\
\hline $0 / 1$ & 1.8 & 3.4 & & \\
\hline
\end{tabular}

As one can see from Table 5, the obtained difference in common relative height of the eyes is $1,1 \%$ (equal to $12,1 \%$ during the experiment, $13,3 \%$ during the simulation), that means that, the difference in percentages in relation to common relative height of the eyes ensured during the experiment is equal to $9,9 \%$. Consequently, it is possible to conclude, that based on the parameters available in technical specifications it is possible to simulate the transmission of PAM-4 modulated signals at $20 \mathrm{~km}$ with the data rate of $25 \mathrm{Gbit} / \mathrm{s}$ accurately enough (ensuring up to $10 \%$ difference in common relative height of the eyes). 
Then, for the model shown at Fig. 10, the evaluation of the affecting factors was performed, as a result, it was concluded, that it is necessary to supplement the proposed model of the mixed solution with the electrical amplifier, as the non-uniformity of the AFR of the electrical amplifier significantly influences BER (up to four BER powers). Moreover, (in addition to further determined affecting factors - dispersion, AFR of the transmitter and noise) it is important to evaluate also the rise time of the pulse as it also significantly influences BER (up to two BER powers).

Improved in the 4.6. chapter, final model of the mixed $25 \mathrm{Gbit} / \mathrm{s}$ (PAM-4), 12,5 Gbit/s (NRZ) WDM-PON transmission system is shown at Fig. 12. In comparison to the model developed in 4.3. chapter, the final model was supplemented with the driving circuit of the modulator considering the conclusions made in 4.5. chapter, as well as with the AFR simulation model offered in 4.2. chapter and realized and evaluated in 4.4. chapter.

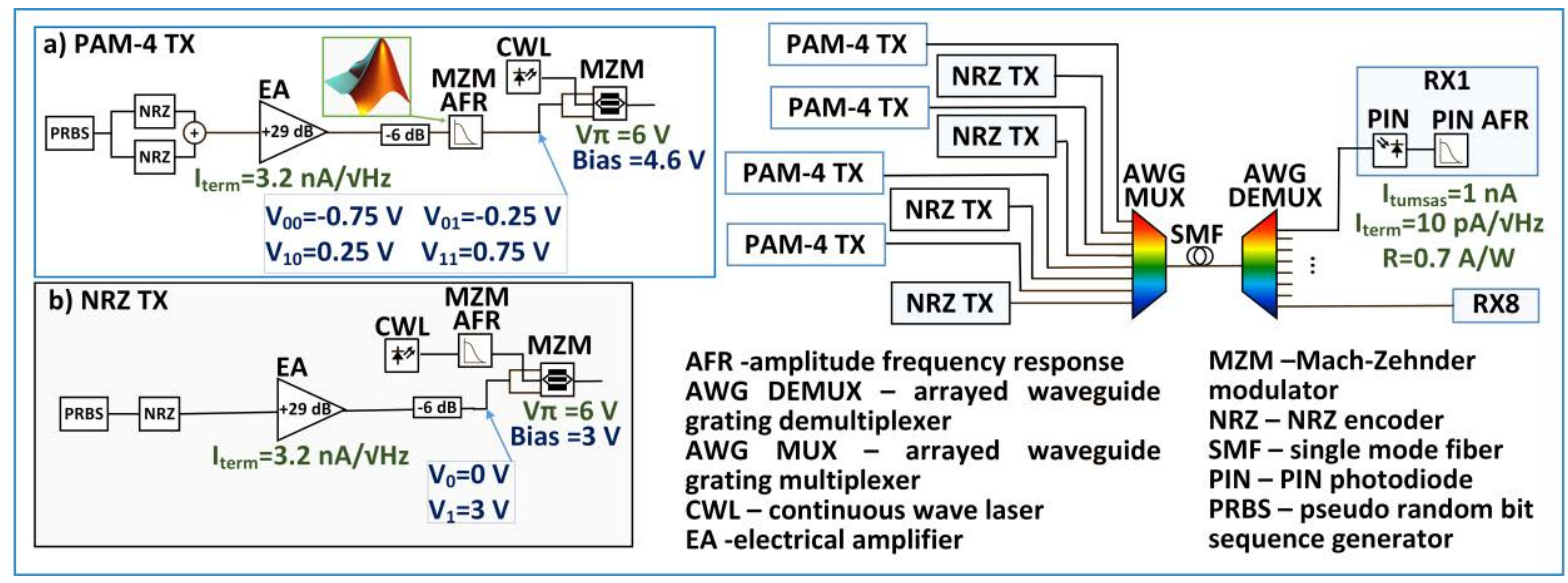

Fig 12. The model of the mixed 25 Gbit/s PAM-4, 12.5 Gbit/s NRZ WDM-PON solution.

Based on the concluded in the previous chapters, the main affecting factors, that it is necessary to consider evaluating the BER ensured by $25 \mathrm{Gbit} / \mathrm{s}$ (PAM-4) WDM-PON are following: AFR of the transmitter, chromatic dispersion, rise time of the pulse as well as the thermal noise of the receiver (that defines the sensitivity of the PIN photoreceiver). The values and limits of the mentioned parameters were obtained in 4.6. chapter.

At the beginning of the research the BER dependence on the rise time of the pulse was evaluated for the different values of the -3 and $-1 \mathrm{~dB}$ of the AFR (that was calculated with the proposed approach) for two values of the chromatic dispersion ( $360 \mathrm{ps} / \mathrm{nm}$ and $460 \mathrm{ps} / \mathrm{nm}$, that corresponds to $20 \mathrm{~km}$, respectively, in optical C and L band) (Fig. 13). Considering the rise time of the pulse generator utilized in the experiment (Keysight M8195A) [19] is equal to $24 \mathrm{ps,}$ the minimal values of $-1 \mathrm{~dB}$ and $-3 \mathrm{~dB}$ bandwidths that is necessary to ensure BER smaller than $1 \times 10^{-3}$ were defined considering this value of the rise time. The values of AFR are equal to, respectively, $5 \mathrm{GHz}$ and $10 \mathrm{GHz}$ for optical $\mathrm{C}$ band and $8 \mathrm{GHz}$ and $14 \mathrm{GHz}$ for optical $\mathrm{L}$ band (Fig. 13). 

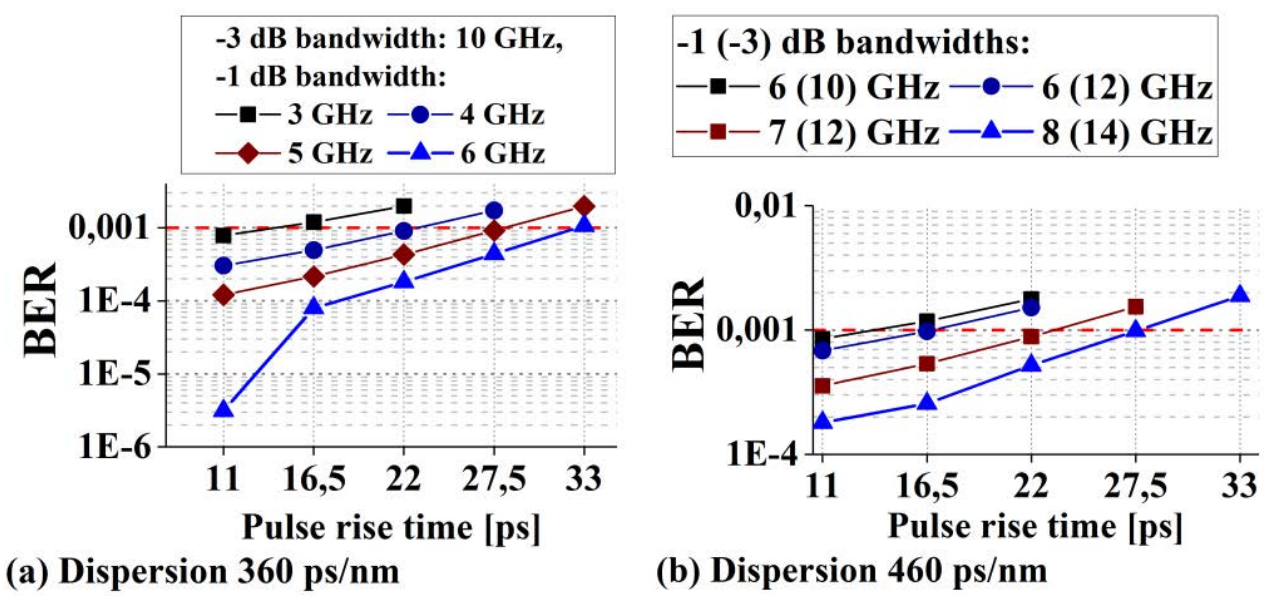

(b) Dispersion $460 \mathrm{ps} / \mathrm{nm}$

Fig. 13. BER dependence on the rise time of the pulse for accumulated dispersion of (a) 360 $\mathrm{ps} / \mathrm{nm}$ and (b) $460 \mathrm{ps} / \mathrm{nm}$.

At the end of the research, the limits of the received optical signal power as well as thermal noise of the receiver were defined. Up to this moment, the value of thermal noise current spectral density equal to $1 \times 10^{-11} \mathrm{~A} / \mathrm{VHz}$, that corresponds to VPI Design Suite default value [29], was utilized in the thesis. In this case the sensitivity of the receiver, that can be calculated utilizing equations (2) and (3) [3], [25] is up to $-20 \mathrm{dBm}$ (with the responsivity equal to $0.7 \mathrm{~A} / \mathrm{W}$ and $-3 \mathrm{~dB}$ bandwidth equal to $10 \mathrm{GHz}$ ).

$$
P_{\text {pin }}=\frac{Q \sigma_{\mathrm{T}}}{R}
$$

where $Q$ is $\mathrm{Q}$ factor (corresponding to certain BER),

$R$ is responsivity, $\mathrm{A} / \mathrm{W}$,

$\sigma_{\mathrm{T}}$ is the root mean square value of the thermal noise current, $\mathrm{A}$ [3].

$$
\sigma_{\mathrm{T}}=\sqrt{S_{\mathrm{T}} \cdot B W},
$$

where $S_{\mathrm{T}}$ is spectral density of the thermal noise, $\mathrm{A}^{2} / \mathrm{Hz}$,

$B W$ is $-3 \mathrm{~dB}$ bandwidth of the receiver, $\mathrm{Hz}$ [25].

While, the sensitivity of the PIN receiver whose AFR was utilized in the thesis, is equal to $-19 \mathrm{dBm}[38]$, that utilizing equations (2) and (3), corresponds to the spectral density of the thermal noise equal to $1.25 \times 10^{-11} \mathrm{~A} / \mathrm{VHz}$. This value was further considered as a threshold, that it is necessary to ensure to conclude, that the solution is feasible utilizing the previously defined minimal values of AFR and commercially available elements of the transmissions system. It is worth to mention that, to ensure more convenient representation of the results, the parameter characterizing the thermal noise was varied with the relation to its initial value $\left(1 \times 10^{-11} \mathrm{~A} / \mathrm{vHz}\right)$ and the relation was described in $\mathrm{dB}$. Respectively, thermal noise current of $1.25 \times 10^{-11} \mathrm{~A} / \mathrm{vHz}$ is 1.25 times or by $2 \mathrm{~dB}$ higher than the reference value $\left(1 \times 10^{-11} \mathrm{~A} / \mathrm{vHz}\right)$. The BER dependence on the limits of the received signal power and thermal noise for the values of the accumulated chromatic dispersion equal to $360 \mathrm{ps} / \mathrm{nm}$ and $460 \mathrm{ps} / \mathrm{nm}$ is shown at Fig. 14. 


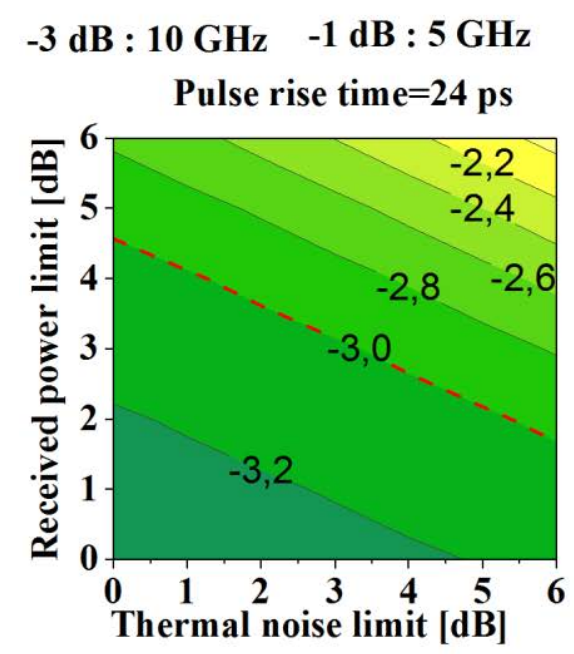

(a) Dispersion $=360 \mathrm{ps} / \mathrm{nm}$

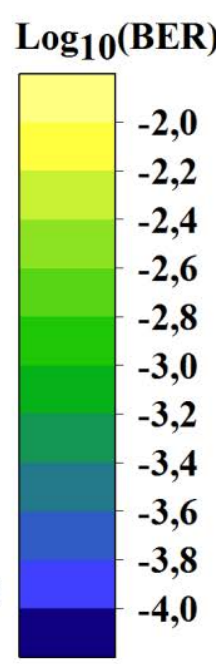

Fig. 14. BER dependence on the limits of the received power and thermal noise for accumulated dispersion of (a) $360 \mathrm{ps} / \mathrm{nm}$ and (b) $460 \mathrm{ps} / \mathrm{nm}$.

As one can see at Fig. 14, in both cases (with accumulated dispersion of $360 \mathrm{ps} / \mathrm{nm}$ and $460 \mathrm{ps} / \mathrm{nm}$ ) it is possible the transmission with BER smaller than $1 \times 10^{-3}$, ensuring the reserve of the thermal noise equal to $2 \mathrm{~dB}$ (that is necessary to ensure sensitivity of $-19 \mathrm{dBm}$ ). It is worth to mention, that in both cases the additional reserve of the received signal power of approximately $3.5 \mathrm{~dB}$ was observed. Consequently, it is possible to conclude that considering the parameters of the commercially available elements in the mixed 12,5 Gbit/s (NRZ) and 25 Gbit/s (PAM-4) WDM-PON transmission system it is possible to ensure transmission at $20 \mathrm{~km}$ in optical C-band with $\mathrm{BER}$, that does not exceed $1 \times 10^{-3}$ utilizing the receiver with the $-3 \mathrm{~dB}$ bandwidth that does not exceed $10 \mathrm{GHz}$, if $-1 \mathrm{~dB}$ bandwidth of the PAM4 transmitter is not smaller than 5 GHz, while in optical L-band - utilizing PAM-4 transmitter with -3 and $-1 \mathrm{~dB}$ bandwidth, that is not smaller than 14 and $8 \mathrm{GHz}$, respectively. 


\section{THE MAIN RESULTS OF THE DOCTORAL THESIS}

\section{The following main conclusions have been drawn during the development of the doctoral thesis.}

1. By evaluating the performance (BER, transmission distance) of the different modulation formats (NRZ-OOK, RZ-OOK, CSRZ-OOK, NRZ-DPSK, RZ-DPSK, CSRZ-DPSK, DB, PAM-4) in WR-WDM-PON transmission systems, it was concluded that for transmission up to $20 \mathrm{~km}$ with $10 \mathrm{Gbit} / \mathrm{s}$ data transmission rate it is necessary to utilize the NRZ-OOK modulation format that is technically simpler to implement, while for longer transmission distances (40 km to $60 \mathrm{~km}$ ) the DB modulation format should be utilized (ensuring the BER reserve of at least 6 BER powers).

2. To perform the increase of the data transmission rate above the $25 \mathrm{Gbit} / \mathrm{s}$ per-channel it is necessary to substitute NRZ-OOK with another data modulation format (PAM-4 or DB) to ensure the transmission distances longer than $5 \mathrm{~km}$ with $40 \mathrm{Gbit} / \mathrm{s}$ or longer than $15 \mathrm{~km}$ with $25 \mathrm{Gbit} / \mathrm{s}$ data transmission rate.

3. It is possible to utilize the transmitters and receivers intended for the transmission with $10 \mathrm{Gbit} / \mathrm{s}$ data rate in WDM-PON transmission system with $25 \mathrm{Gbit} / \mathrm{s}$ per-channel data transmission rate as well as to ensure channel spacing of $50 \mathrm{GHz}$ if the PAM-4 modulation format is utilized, while utilizing DB modulation format with transmitters and receivers intended for $20 \mathrm{Gbit} / \mathrm{s}$ data transmission rate and $100 \mathrm{GHz}$ channel spacing it is possible to ensure BER below $1 \times 10^{-3}$ with $3 \mathrm{~dB}$ smaller received optical signal power (in comparison to PAM-4).

4. In the PAM-4 modulated WR-WDM-PON transmission system with the per-channel data rate of $25 \mathrm{Gbit} / \mathrm{s}$ the smallest BER is ensured if the spectrum of the signal in the transmitter is kept in frequency band before $10 \mathrm{GHz}$, while from 10 to $15 \mathrm{GHz}$ it is filtered, moreover the amplitude-frequency response around $0 \mathrm{~Hz}$ has significant impact on the BER (about five BER powers).

5. In the mixed 12,5 Gbit/s (NRZ) and $25 \mathrm{Gbit} / \mathrm{s}$ (PAM-4) WDM-PON transmission system the utilization of MLR mixed solution, as well as decrease of the channel spacing to $50 \mathrm{GHz}$ does not affect the performance (BER, minimal received optical signal power) of transmission system significantly (not more than one BER power or 1 $\mathrm{dB}$ ), while the main factors that affect the transmission of PAM-4 channels, similarly to 25 Gbit/s (PAM-4) WDM-PON, are following: chromatic dispersion, amplitudefrequency response of the transmission system, the thermal noise of the receiver and pulse rise time.

In the thesis, the results of the finished research are summarized as well as possible directions for further investigation are defined.

1. The development of the general method for the modelling of the amplitude-frequencyresponse of the transmitter.

2. The utilization of digital signal processing for minimization of the impact of the main factors limiting the performance of high data rate (above $25 \mathrm{Gbit} / \mathrm{s}$ ) access networks (chromatic dispersion, frequency response of the elements). 


\section{LITERATURE}

[1] Agalliu, R., Lucki, M. Benefits and limits of modulation formats for optical communications// Advances in Electrical and Electronic Engineering. - 2014. - vol. 12 (2) - pp. 160-167.

[2] Agalliu, R., Lucki, M. System performance and limits of optical modulation formats in dense wavelength division multiplexing systems// Elektronika ir Elektrotechnika. - 2016 - vol. 22 (2) - pp. 123-129.

[3] Agrawal G. P. Fiber-Optic Communications Systems, Third Edition. - John Wiley \& Sons, Inc., 2002. - pp. 563.

[4] Andrade M. D., Kramer G., Wosinska L., Chen J., Sallent S., Mukherjee B. Evaluating strategies for evolution of passive optical networks// IEEE Communications Magazine. 2011 - vol. 49, no. 7 - pp. 176-184.

[5] Chen A., Murphy E. Broadband Optical Modulators: Science, Technology, and Applications. 1st Edition - CRC Press, 2011. - pp. 568.

[6] Eiropas Komisija. Komisijas ieteikums (2010. gada 20. septembris) par regulētu piekḷuvi nākamās paaudzes piekḷuves (NGA) tīkliem. - Eiropas Savienības Oficiālais Vēstnesis, 2010. - 1pp. 35-47.

[7] Eiselt N. et al. Real-time evaluation of 26-GBaud PAM-4 intensity modulation and direct detection systems for data-center interconnects// Proceedings of Optical Fiber Communications Conference and Exhibition (OFC). - Anaheim, Canada - 2016. - pp. 1-3.

[8] European Commission. Europe's Digital Progress Report - 2017, Telecoms chapter. Slovenia. - 2017. - pp. 8.

[9] Fibre to the Home Council Europe, D\&O Committee. FTTH Handbook Edition 7. Wettelijk Depot, 2014. - pp 187.

[10] Forzati M., et al. Next-Generation Optical Access Seamless Evolution: Concluding Results of the European FP7 Project OASE// IEEE/OSA Journal of Optical Communications and Networking. - 2015. - vol. 7, no. 2 - pp. 109-123.

[11] FTTH Council Europe. Case studies collection. - 2016 - 74 pp.

[12] FTTH Council Europe. Press Release: Breaking news from the FTTH Conference 2017: Austria \& Serbia join the Global FTTH Ranking Latvia reaches pole position in European FTTH penetration. -2017 . -3 pp.

[13] Gao J. Demonstration of the first 29dB power budget of 25-Gb/s 4-PAM system without optical amplifier for next generation access network// Proceedings of Optical Fiber Communications Conference and Exhibition (OFC). - Anaheim, Canada - 2016. - pp. 1-3.

[14] Gao J., Lin H., Liu X., Wu X., Zhou L., Yao S. Flexible 2/4-PAM-Modulation 25-Gb/s PON for Next Generation Access Network// Proceedings of ECOC 2016; 42nd European Conference on Optical Communication. - Dusseldorf, Germany - 2016. - pp. 1-3.

[15] ITU-T G.984.1. Gigabit-capable passive optical networks (GPON): General characteristics ITU-T// International Telecommunication Union. - 2008. - pp. 43. 
[16] ITU-T G.989.2. 40-Gigabit-capable passive optical networks 2 (NG-PON2): Physical media dependent (PMD) layer specification// International Telecommunication Union. 2014. - pp. 108.

[17] ITU-T G.989.2. Amendment 2, 40-Gigabit-capable passive optical networks 2 (NGPON2): Physical media dependent (PMD) layer specification. Amendment 2// International Telecommunication Union. - 2017. - pp. 120.

[18] iXBlue. Technical Specification: MX-LN series $1550 \mathrm{~nm}$ band intensity modulators. pp. 6.

[19] Keysight Technologies. Keysight M8195A Arbitrary Waveform Generator. Revision 2. 2017. - pp. 267.

[20] Larsen C. P., Gavler A., Wang K. Comparison of active and passive optical access networks// Proceedings of 9th Conference of Telecommunication, Media and Internet, Ghent $-2010 .-$ pp. 1-5.

[21] Latal J. et al. Simulation of modulation formats for optical access network based on WDMPON// Proceedings of 16th International Conference on Transparent Optical Networks (ICTON). - Graz, Austria - 2014 - pp. 1-7.

[22] Lazarou I., Dris S., Bakopoulos P., Schrenk B., Avramopoulos H. Full-Duplex 4-PAM Transmission for Capacity Upgrade in Loop-Back PONs// IEEE Photonics Technology Letters. - 2013. - vol. 25, no. 12 - pp. 1125-1128.

[23] Miao X., Bi M., Fu Y., Li L., Hu W. Experimental Study of NRZ, Duobinary, and PAM4 in O-Band DML-Based 100G-EPON// EEE Photonics Technology Letters - 2017. - vol. 29, no. 17 - pp. $1490-1493$.

[24] Nesset D. PON roadmap [invited]// Journal of Optical Communications and Networking - 2017. - vol. 9, no. 1 - pp. 71-76.

[25] Optiwave, Tutorial: Receiver Sensitivity. - pp. 2.

[26] Sun C., Bae S. H., Kim H. Transmission of 28-Gb/s Duobinary and PAM-4 Signals Using DML for Optical Access Network// EEE Photonics Technology Letters - 2017 - vol. 29 (1) - pp. 130-133.

[27] Van der Linden R., Tran N., Tangdiongga E., Koonen T. Increasing flexibility and capacity in real PON deployments by using 2/4/8-PAM formats// Proceedings of Optical Fiber Communications Conference and Exhibition (OFC) - Anaheim, Canada - 2016. pp. 1-3.

[28] Van der Vorst T., Brennenraedts R., Driesse M., Bekkers R. Beyond fast. How the speed of residential internet access will develop between now and 2022. - Utrecht, 2016 - pp. 44.

[29] VPIphotonics GmbH. Photonic modules. - 2017.

[30] Wei J. et al. Demonstration of the First Real-Time End-to-End 40-Gb/s PAM-4 for NextGeneration Access Applications Using 10-Gb/s Transmitter// Journal of Lightwave Technology - 2016. - vol. 34, no. 7 - pp. 1628-1635.

[31] Wei J. L., Grobe K., Griesser H. Cost-efficient high-speed modulation for next-generation PONs photonic networks // In Proceedings of 16. ITG Symposium. - Leipzig, Germany 2015. - pp. 1-4. 
[32] Wei J. L., Grobe K., Sanchez C., Giacoumidis E., Griesser H. Comparison of cost-and energy-efficient signal modulations for next generation passive optical networks// Optics Express - 2015 - vol. 23 (22) - pp. 28271-28281.

[33] Wei L., Grobe K., Wagner C., Giacoumidis E., Griesser H. 40 Gb/s lane rate NG-PON using electrical/optical duobinary, PAM-4 and low complex equalizations"// In Proceedings of Optical Fiber Communications Conference and Exhibition (OFC), Anaheim, Canada - 2016 - pp. 1-3.

[34] Ye C., Hu X., Zhang K. Demonstration and Analysis on PAM-4/8, DB-PAM-2/4 and DMT Formatted TDM-PON with 25Gbps, 40Gbps, 50Gbps Capacity per Lane using Economical 10Gbps// Proceedings of ECOC 2016; 42nd European Conference on Optical Communication. - Dusseldorf, Germany - 2016 - pp. 1-3.

[35] Yi L. et al. Field-Trial of a Real-Time 100 Gb/s TWDM-PON Based on 10G-Class Optical Devices// In Proceedings of ECOC 2016; 42nd European Conference on Optical Communication. - Dusseldorf, Germany - 2016. - pp. 1-3.

[36] Coolbox: Infrastructure and equipment. / Internet. - https://www.cooolbox.bg/za-nas.

[37] DiFazio B: The Fusion of Fronthaul and Backhaul: What it Means for 5G", 2016. / Internet. - https://www.rcrwireless.com/20161115/sponsored/fusion-fronthaul-backhaulmeans-5g.

[38] Discovery Semiconductors Inc.: $10 \mathrm{GHz}$ Linear InGaAs PIN+TIA Optical Receiver with Optional CDR. / Internet. https://www.discoverysemi.com/Product_Pages/DSCR402PIN.php.

[39] FOT: Gigabit-capable Passive Optical Networks (GPON) Equipment Market Research 2017. / Internet. - https://www.fiberoptictel.com/gepongpon-equipment-market-research2017-2022-brief/.

[40] FSAN (Full servise acces network): FSAN roadmap, 2016. / Internet. http://www.fsan.org/roadmap/.

[41] Keysight Technologies: How Do I Measure the Bit Error Rate (BER) to a Given Confidence Level on the J-BERT M8020A and the M8040A High-Performance BERT? / Internet.

https://www.keysight.com/main/editorial.jspx?ckey=1481106\&id=1481106\&nid=11143.0.00\&lc $=$ eng\&cc $=$ LV.

[42] Keysight Technologies: Using Eye Diagrams. / Internet.

http://na.support.keysight.com/plts/help/WebHelp/Analyzing/Analyzing_Data_using_Ey e_Diagrams.html\#PAM2_PAM4.

[43] Lightwave Online: Starman deploys 10G EPON in Estonia, 2016. / Internet. http://www.lightwaveonline.com/articles/2016/06/starman-deploys-10g-epon-inestonia.html.

[44] MathWorks: Documentation: spline. / Internet. https://www.mathworks.com/help/matlab/ref/spline.html. 